\title{
DNA methylation patterns in tissues from mid-gestation bovine foetuses produced by somatic cell nuclear transfer show subtle abnormalities in nuclear reprogramming
}

\author{
Christine Couldrey, Rita SF Lee
}

\begin{abstract}
Background: Cloning of cattle by somatic cell nuclear transfer (SCNT) is associated with a high incidence of pregnancy failure characterized by abnormal placental and foetal development. These abnormalities are thought to be due, in part, to incomplete re-setting of the epigenetic state of DNA in the donor somatic cell nucleus to a state that is capable of driving embryonic and foetal development to completion. Here, we tested the hypothesis that DNA methylation patterns were not appropriately established during nuclear reprogramming following SCNT. A panel of imprinted, non-imprinted genes and satellite repeat sequences was examined in tissues collected from viable and failing mid-gestation SCNT foetuses and compared with similar tissues from gestation-matched normal foetuses generated by artificial insemination (Al).

Results: Most of the genomic regions examined in tissues from viable and failing SCNT foetuses had DNA methylation patterns similar to those in comparable tissues from Al controls. However, statistically significant differences were found between SCNT and Al at specific CpG sites in some regions of the genome, particularly those associated with SNRPN and KCNQ1OT1, which tended to be hypomethylated in SCNT tissues. There was a high degree of variation between individuals in methylation levels at almost every $\mathrm{CpG}$ site in these two regions, even in Al controls. In other genomic regions, methylation levels at specific $\mathrm{CpG}$ sites were tightly controlled with little variation between individuals. Only one site (HAND1) showed a tissue-specific pattern of DNA methylation. Overall, DNA methylation patterns in tissues of failing foetuses were similar to apparently viable SCNT foetuses, although there were individuals showing extreme deviant patterns.

Conclusion: These results show that SCNT foetuses that had developed to mid-gestation had largely undergone nuclear reprogramming and that the epigenetic signature at this stage was not a good predictor of whether the foetus would develop to term or not.
\end{abstract}

\section{Background}

Somatic cell nuclear transfer (SCNT) has been used to successfully produce cloned animals from several mammalian species since a sheep was cloned using a differentiated somatic donor cell [1]. However, to date widespread application of SCNT in agricultural breeding programs has not yet been captured because the technology remains inefficient despite more than 10 years of

\footnotetext{
* Correspondence: rita.lee@agresearch.co.nz

AgResearch, Reproductive Technologies Group, Ruakura Research Centre, East Street, Private Bag 3123, Hamilton, New Zealand
}

research. Irrespective of the species being cloned, there is still a high rate of pregnancy failure throughout gestation [2-6]. The most common SCNT foetal phenotypes across species are foetal overgrowth and loss of allometric growth regulation (collectively known as "large offspring syndrome"), musculoskeletal defects, and acute, excessive accumulation of allantoic fluid (hydrallantois or hydrops) accompanied by perturbations in the composition of this fluid [7]. In cattle, the large offspring syndrome appears to be independent of the donor cell genetics.

Many of the developmental defects observed in cloned bovine foetuses suggest the involvement of growth 
regulating genes, particularly those known to be imprinted. Some of these genes play key roles in regulating cellular proliferation, growth and development of the foetus and the placenta (reviewed [8]). The phenotypes commonly observed in SCNT foetuses bear many similarities to some of those seen in experimentally-created imprinting disruptions in mice (silencing of both alleles or biallelic expression of imprinted genes), or to naturally-occurring human syndromes, such as Beckwith-Wiedemann syndrome (BWS) [9-13]. These similarities suggest that the expression of some of these imprinted genes is abnormal and/or that these genes are not appropriately reprogrammed following SCNT. Furthermore, SCNT calves dying shortly after birth were shown to have abnormal expression of imprinted genes in a variety of organs when compared to controls generated by AI [14]; this was not the case in surviving adult clones $[15,16]$. During the development of multicellular organisms, different cells and tissues acquire different programs of gene expression. It is thought that a substantial part of this gene regulation is mediated through epigenetic modifications such as DNA methylation, histone tail modifications and the binding of non-histone proteins to chromatin [17-19] so that each somatic cell in the organism has its own epigenetic signature (epigenome) which reflects its genotype, developmental history and environmental influences, which ultimately determines the phenotype of the cell and the organism. This is clearly illustrated in the events following fertilization, where the majority of the genome undergoes active paternal demethylation, then passive maternal demethylation. Re-methylation of the genome then occurs during repeated mitosis as cells progress towards lineage commitment and the development of the embryo proper and the placenta [18,20-22]. How the developmental programs are coordinated and orchestrated from the genomic blueprint is still poorly understood, even in normal development.

In reproductive cloning by SCNT, the epigenetic signature of a differentiated somatic cell must be reset to a state resembling totipotency, capable of driving full development after fusion of the cell with an enucleated oocyte cytoplast. Incomplete nuclear reprogramming is widely postulated to be a major contributor to the low developmental success rate following SCNT. Evidence to support this include observed hypo-methylation [23-26], hyper-methylation $[27,28]$, or mosaic methylation states [29] in tissue samples collected from abnormal foetuses or cloned calves that died shortly after birth. Normal methylation following SCNT has also been reported $[28,30,31]$, suggesting a degree of stochasticity in nuclear reprogramming. The variable findings from different studies are due to different genes or genomic regions examined, different tissues used and controls that were not gestation- or age-matched. This has made comparisons between previous studies difficult.
Cloned animals that reach maturity are able to reproduce normally and give rise to normal offspring without the high rate of pregnancy failure or large offspring syndrome associated with SCNT [32,33], suggesting that underlying cause/s of the abnormalities associated with SCNT is/are epigenetic.

In this study, we examined the DNA methylation patterns in a panel of candidate genes using tissues from three foetal organs (liver, kidney and adrenal glands) of similar gestations generated by either SCNT or AI. These organs were selected because of the pivotal roles they play in foetal metabolism, nutrient sensing and hematopoiesis (liver), regulation of blood pressure and foetal fluid homeostasis (kidney) and foetal endocrinology (adrenal glands). As most cases of hydrallantois occur from or just after mid-gestation, the selection of this stage of gestation allowed us to compare samples from foetuses that showed clear physiological and anatomical abnormalities with those that had not yet exhibited these symptoms and thus, had the potential to develop to further.

The genes selected consisted of those known to be imprinted in other species, non-imprinted genes and repeat sequences (satellites 1,2 and alpha). The imprinted genes include those associated with BWS, such as IGF2, KCNQ1, CDKN1C, KCNQ1OT1; others such as ASCL2, HAND1, DIO3; and SNRPN, a gene in the Prader-Willi and Angelman syndrome locus. The non-imprinted genes include colony stimulating factor (CSF-1), STAT5a, DKK-1, and GR, which codes for the glucocorticoid receptor, that mediates the action of glucocorticoids and mineralcorticoids, both important in regulation of fluid composition. The $\mathrm{CpG}$ islands examined included those located upstream of transcriptional start sites or within the gene itself or in equivalent regions shown in other species to be differentially methylated regions (DMRs) and normally associated with imprinted genes. The SNRPN site is equivalent to the imprinting centre (IC) of the human gene [34] which has been shown to be aberrantly methylated in the Prader-Willi (PWS) and Angelman syndromes [35]. The KCNQ1OT1 region is equivalent to the human KCNQ1OT1 DMR which was found to be hypomethylated at increased frequency in human IVF offspring $[12,36,37]$. Together, this selection of genomic sequences allowed us to assess how well these different regions were re-programmed after nuclear transfer in embryos that were capable of developing at least to mid-gestation.

\section{Results}

Pregnancy rates in SCNT and Al

From the first ultrasound scan at Day 35, 29 of the 42 (69\%) SCNT recipient dams that received a Day 7 
blastocyst were found to be pregnant. By Day 130, just 10 days prior to the development of the first SCNT hydrops case, only 14 were still pregnant (33\%). Four subsequently developed clinical hydrops and were slaughtered. For the AI group, 13 of the $18(72 \%)$ recipients inseminated were pregnant at Day 35, 11 of these still pregnant (61\%) at Day 130; none showed signs of abnormal fluid accumulation.

\section{DNA methylation analysis}

DNA methylation analysis at each of the listed genomic regions was performed from the same genomic DNA for each sample. Because the cleavage of the transcribed RNA is sequence-specific, some fragments may contain only one CpG site whilst others may contain up to 6 CpG sites where the CpG dinucleotides were arranged consecutively in the sequence or close together. Where multiple CpG sites occurred within a fragment, the methylation level reported by the EpiTYPER software was that of the most highly methylated site. Where is was not possible to resolve two fragments with the same mass but with different sequences, the methylation level is recorded as an average of the two fragments. The number of $\mathrm{CpG}$ sites or group of sites that could be analyzed for each region is given in each figure legend.

\section{Imprinted genes}

\section{IGF2 exon 10}

The CpG island located in IGF2 exon 10 was highly methylated (70-100\%) at almost all CpG sites in all three tissues examined and in all treatment groups (figure 1). There was a high level of variation in methylation levels between individual samples, even in normal control tissues. Only the adrenal tissues showed a significant difference in mean methylation between AI, SCNT and SCNT-hydrops groups; SCNT-hydrops samples tended to be hypermethylated compared with the AI or SCNT samples. At CpG 5, individual SCNT and SCNT-hydrops adrenal samples were either completely methylated or unmethylated, whereas the AI samples were methylated to between $30-40 \%$. No notable tissue-specific methylation patterns were observed. When averaged over the entire region analyzed, the methylation levels ranged from 65 to $85 \%$ for all three tissues (figure 1d). A significant difference was detected in the regional mean methylation levels between the $\mathrm{AI}$ and SCNT $(P=0.01)$ and SCNT-hydrops $(P=0.03)$ in the adrenal samples, and in the kidney between $\mathrm{AI}$ and SCNT $(\mathrm{P}=0.04)$ and between SCNT and SCNThydrops $(\mathrm{P}<0.001)$. Three of the SCNT-hydrops samples were almost $100 \%$ methylated at every site whilst another was methylated at between $40-50 \%$ at almost every site, illustrating the level variation between some individuals in this group.

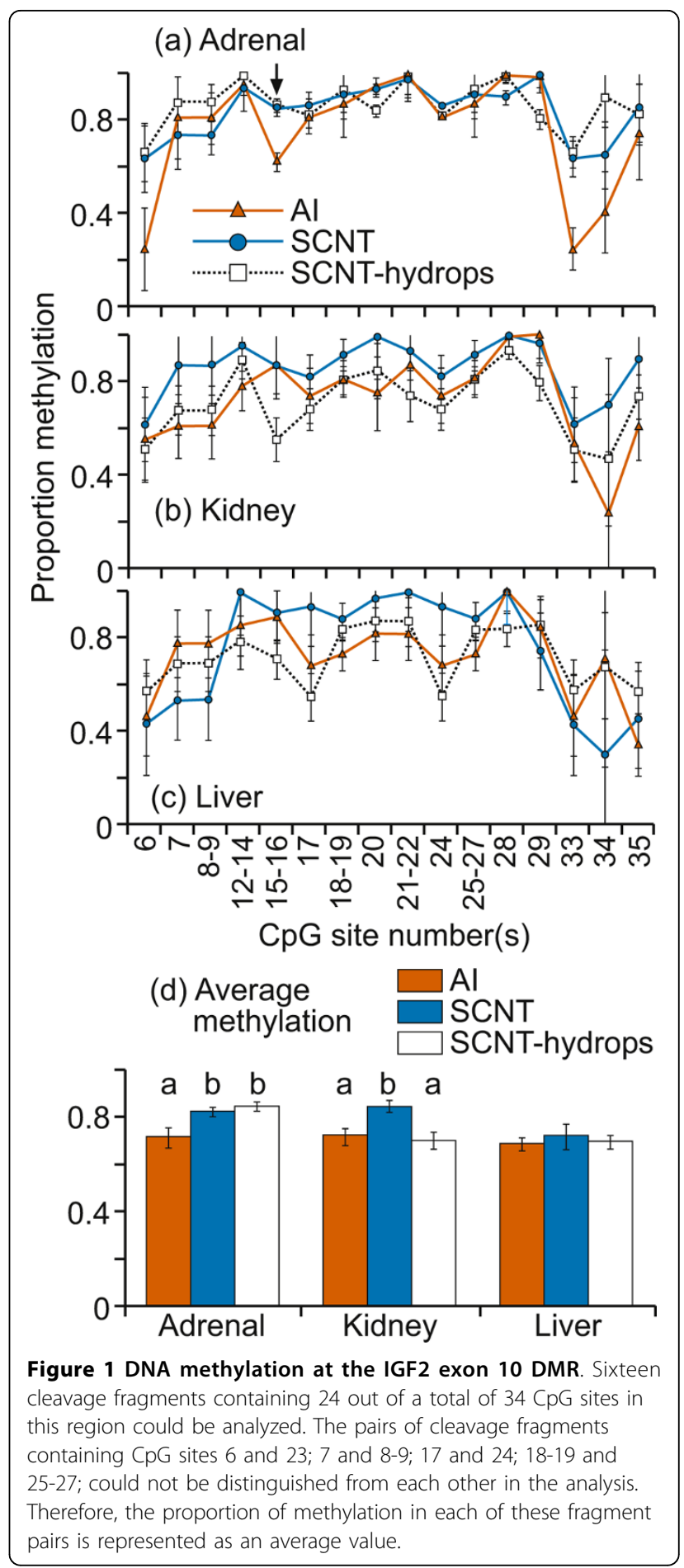

ASCL2

Compared with the IGF2 exon 10 region, the DNA methylation levels here were low (less than 25\%) in all tissue samples (figure 2). Furthermore, the variation between individuals was very small in all three tissues, resulting in a mean percentage methylation at each CpG site that was remarkably similar between the treatment 


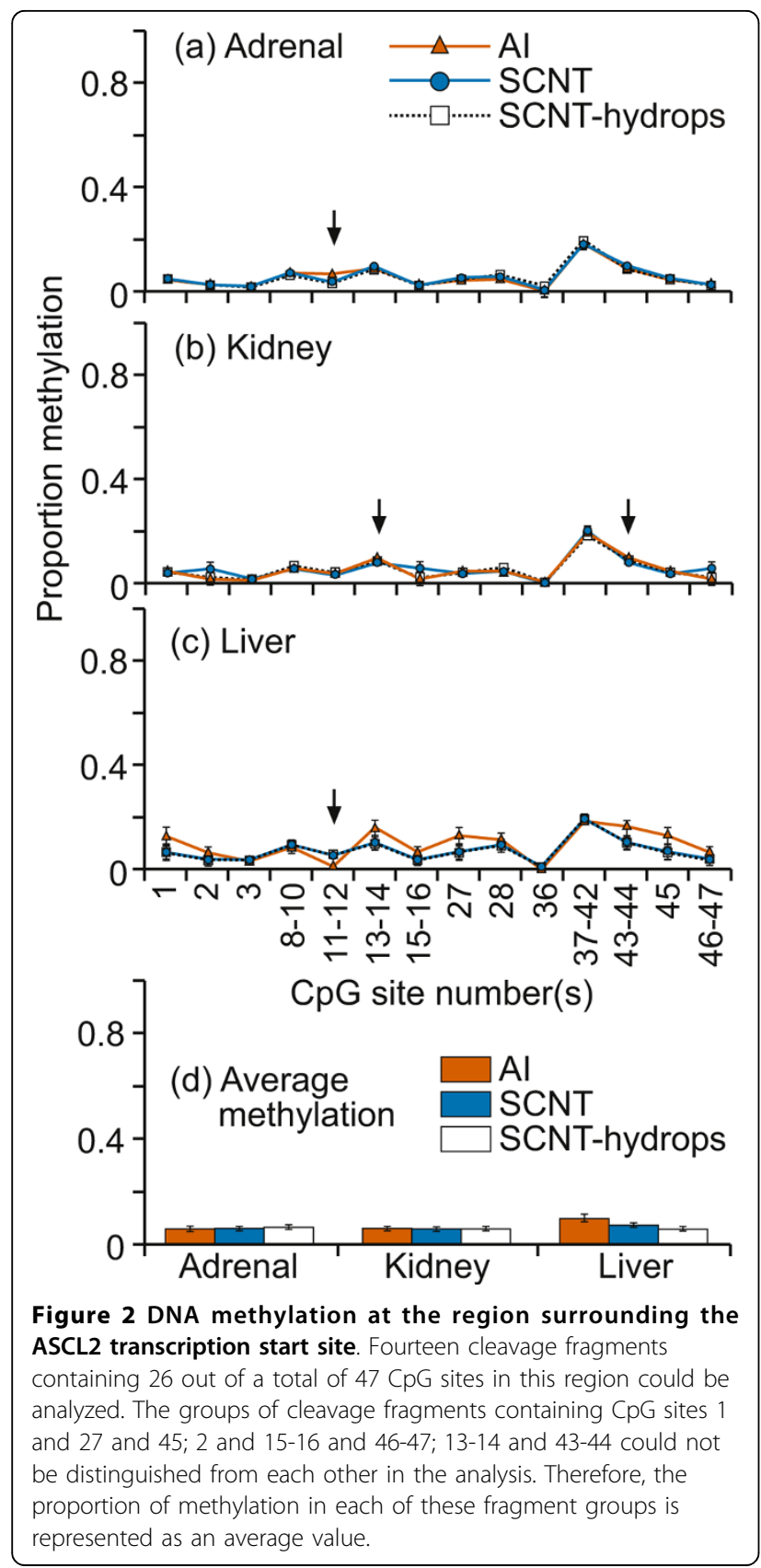

groups. The fragment containing CpG sites $37-42$ was consistently methylated at higher levels $(20-25 \%)$ compared with other fragments/sites (0-10\%) examined in every sample. This difference is likely due to the algorithm used by EpiTYPER to determine methylation levels in fragments containing multiple CpG sites [38]. Despite the apparent similarity in mean methylation levels in the fragments analyzed, significant differences between AI, SCNT and SCNT-hydrops groups were found in certain fragments in all three tissues (figure 2). The mean DNA methylation level across this region was similar in all groups across all tissues (figure 2d).
HAND1

DNA methylation levels at this $\mathrm{CpG}$ island in the promoter region of HAND1 were mostly low (0-20\%) in kidney and liver tissues (figure 3). Interestingly, the adrenal tissues from all three groups showed higher methylation levels (10-55\%) and greater variability at most CpG sites across this region when compared with either liver or kidney samples. The only statistically significant difference in the mean methylation levels between treatment groups was in the liver (figure 3c); however the difference in methylation levels was very

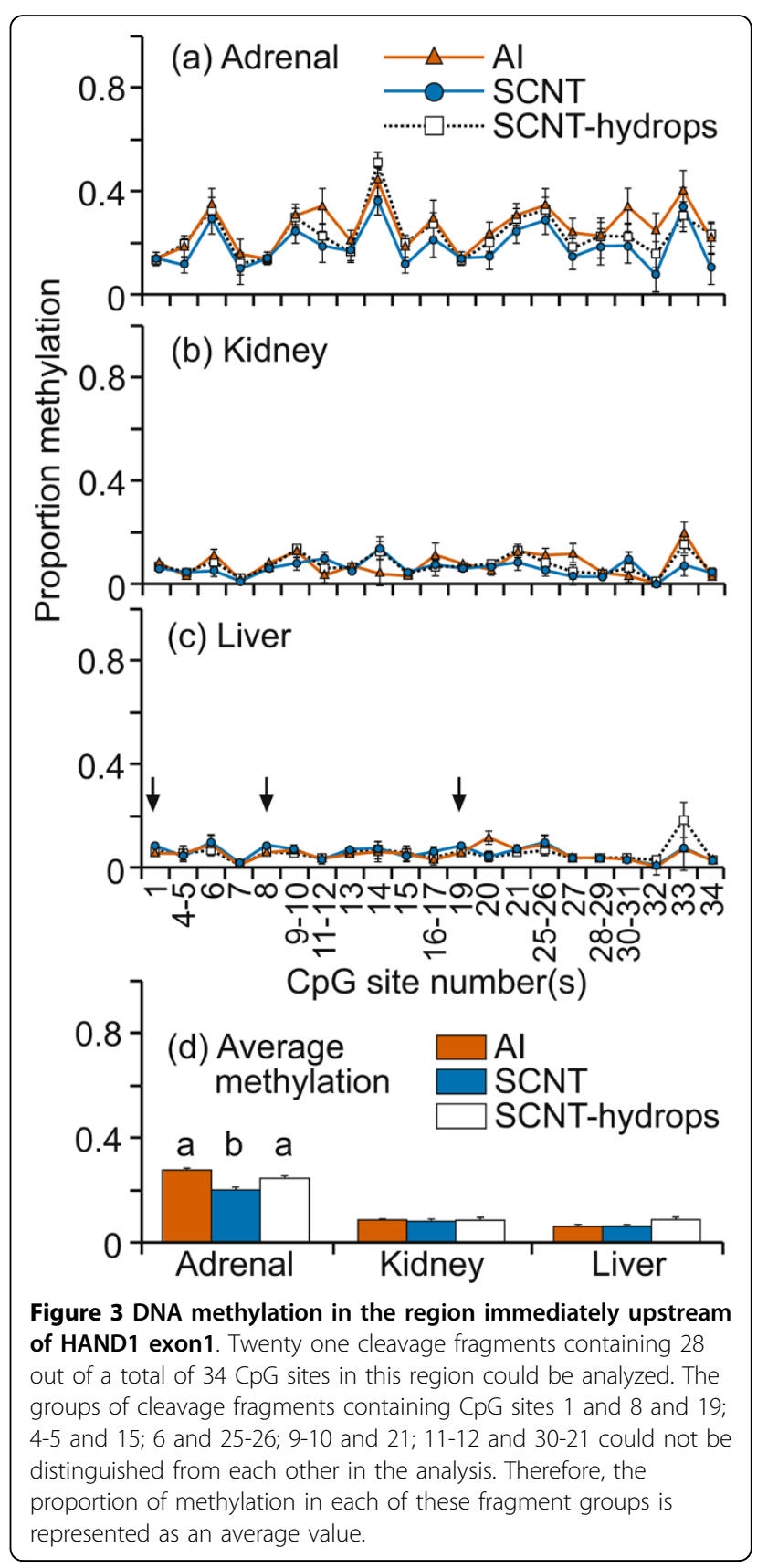


small. Otherwise, DNA methylation levels at individual CpG site/s were not different among the treatment groups. The mean level of DNA methylation across the region was similar between the groups in kidney and liver tissues but a significant difference was observed in adrenal tissue (figure 3d) where SCNT samples were significantly less methylated compared with either AI or SCNT-hydrops samples $(\mathrm{P}<0.002)$. For the adrenal tissues, within the SCNT-hydrops group, there were two individuals cloned from the same donor somatic cell line: one was consistently methylated to between 30 $70 \%$ at practically every analyzable $\mathrm{CpG}$ site whereas the other was methylated to only about $10 \%$ for all but three analyzable CpG sites.

KCNQ1

The percentage of DNA methylation in the KCNQ1 region examined varied from $0-45 \%$ across individual CpG sites, with most showing less than $20 \%$ methylation (figure 4). Overall, the methylation levels of the samples from all three groups were similar at individual $\mathrm{CpG}$ sites in all tissues examined, although significant differences among the groups were detected in some fragments (figure 4a and 4c). No tissue-specific methylation patterns were observed and the homogeneity of the methylation levels in all the samples was reflected in the lack of difference in the mean regional methylation levels between the tissues and groups examined (figure 4d).

\section{CDKN1C}

The methylation pattern in this CpG island, which is within the transcribed region of CDKN1C, was very similar across all groups and in all tissues (figure 5). There was little variation at practically every $\mathrm{CpG}$ site between individual samples within each treatment group; this lack of variation is reflected in the similarity of the regional mean methylation levels (figure $5 \mathrm{~d}$ ). The mean methylation levels at individual $\mathrm{CpG}$ sites or groups of CpG sites were between $0-20 \%$ with the exception of one cleavage fragment containing CpG1316 , which was methylated to $40-45 \%$ in every group and tissue examined. Because this fragment contains four CpG sites, it was not possible to determine if certain sites were methylated to a greater extent than others. CpG6 and CpG22, 23 were always completely unmethylated in every sample. Due to the limited variation between individual samples in this region, even differences as small as $2-3 \%$ showed statistical significance at some sites (figure $5 \mathrm{~b}$ ).

\section{SNRPN}

The methylation levels at each CpG site/groups of sites in this region showed a high degree of variation between individuals in all three tissues and in every treatment group (figure 6). Although the majority of the sites showed no significant differences in mean methylation levels between the treatment groups, DNA from AI

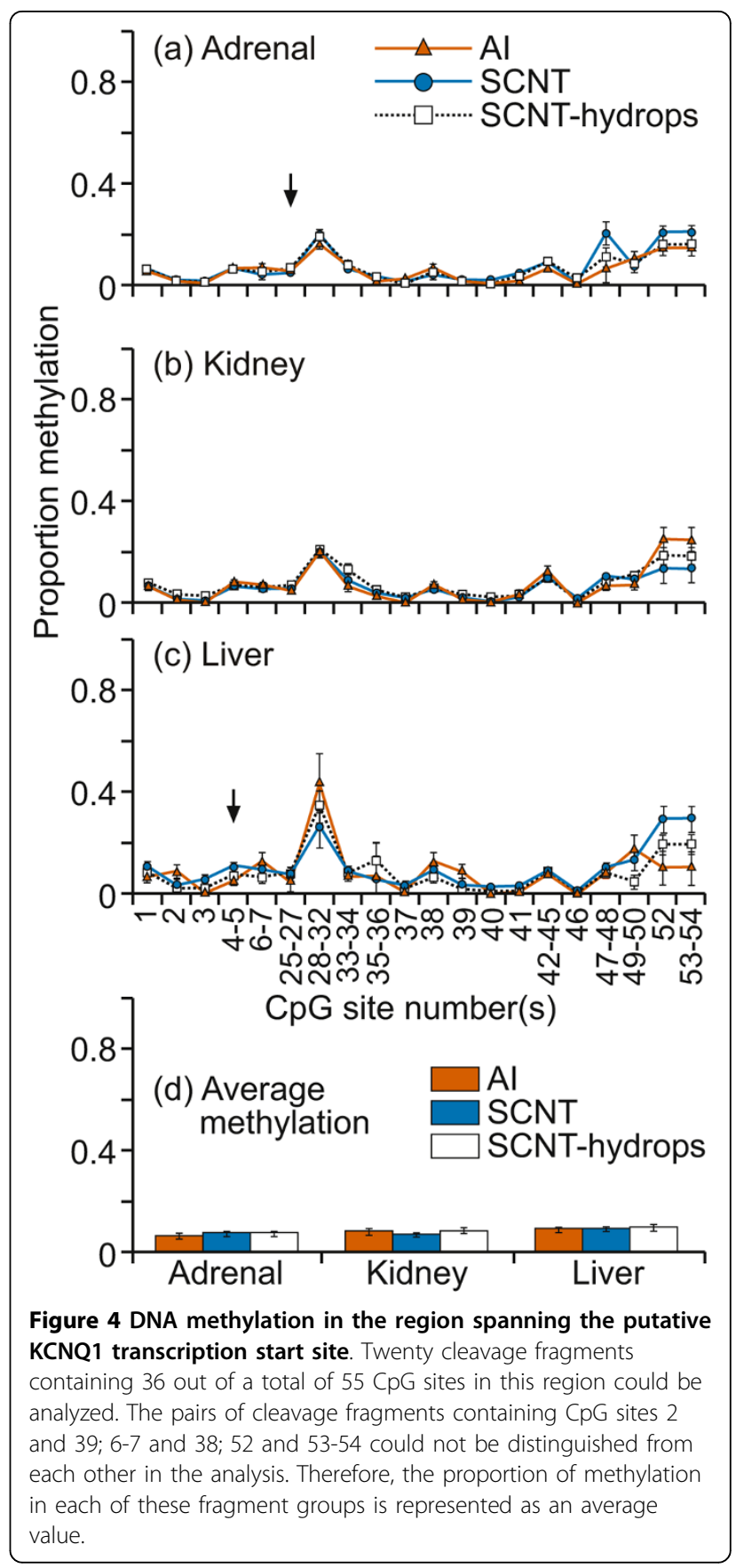

samples tended to be more methylated than SCNT or SCNT-hydrops, particularly for the adrenal and kidney samples. In these two organs, the methylation levels in the AI samples ranged between $30-100 \%$ for most CpG sites whereas in the adrenal samples, three each of the SCNT and SCNT-hydrops samples were almost unmethylated $(<10 \%)$; the others were methylated to a similar extent as the AI samples. Similarly low levels of methylation in individual SCNT and SCNT-hydrops kidney samples were also observed. Only one SCNT and 


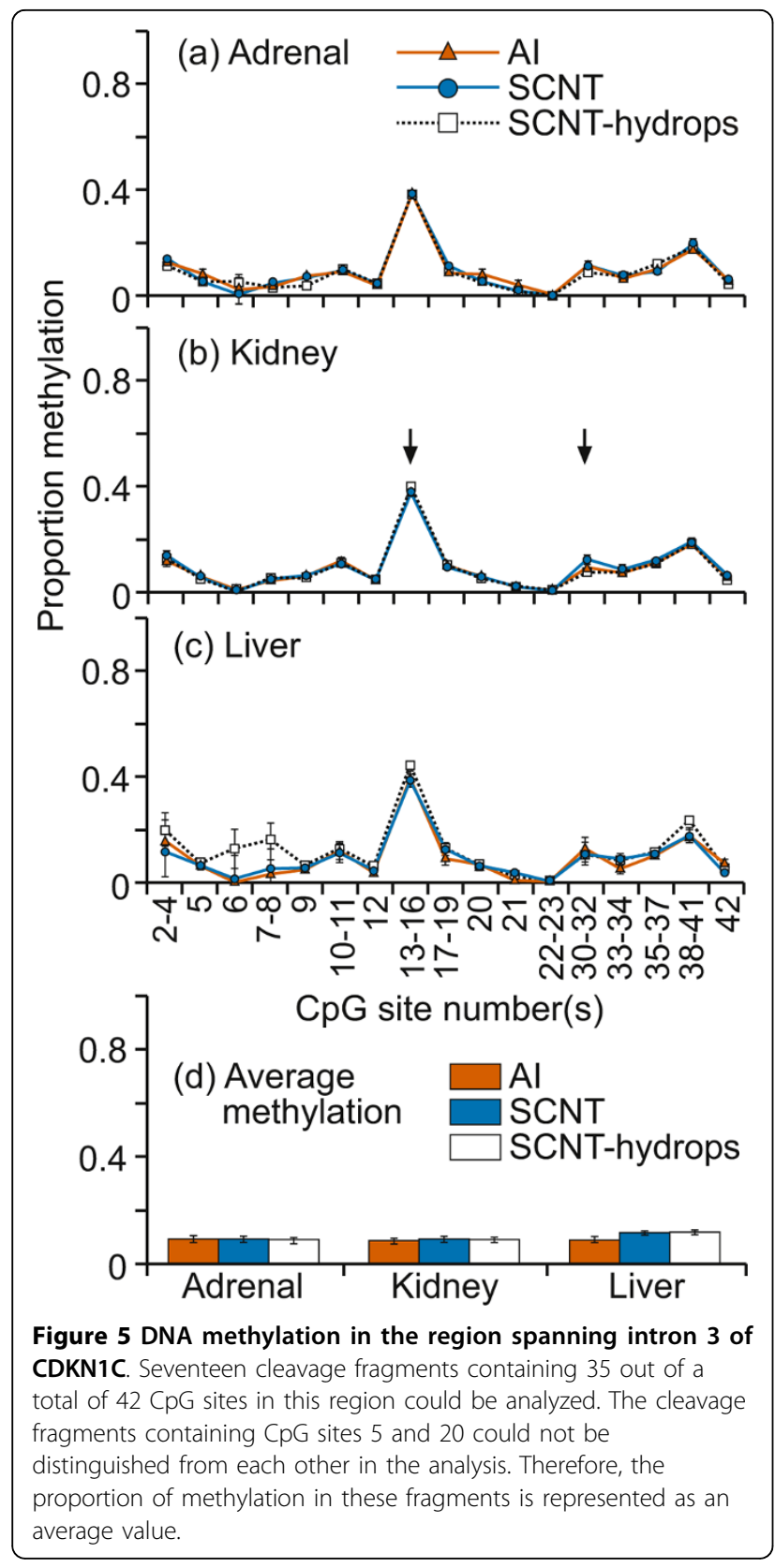

one SCNT-hydrops foetus both showed consistent hypomethylation in all three tissues whilst others that were hypomethylated in one tissue showed almost normal methylation levels in other tissues. The regional mean methylation levels were significantly higher $(\mathrm{P}<0.001)$ in the AI adrenal and kidney but not liver samples when compared with SCNT or SCNT-hydrops (figure 6d). Only two fragments in kidney tissues showed significant difference in mean methylation levels (AI $>\mathrm{SCNT}$, SCNT-hydrops, figure 6b).

A cleavage fragment containing $\mathrm{CpG}$ sites 7,8 , and 9 was consistently methylated to $\leq 10 \%$ in every sample

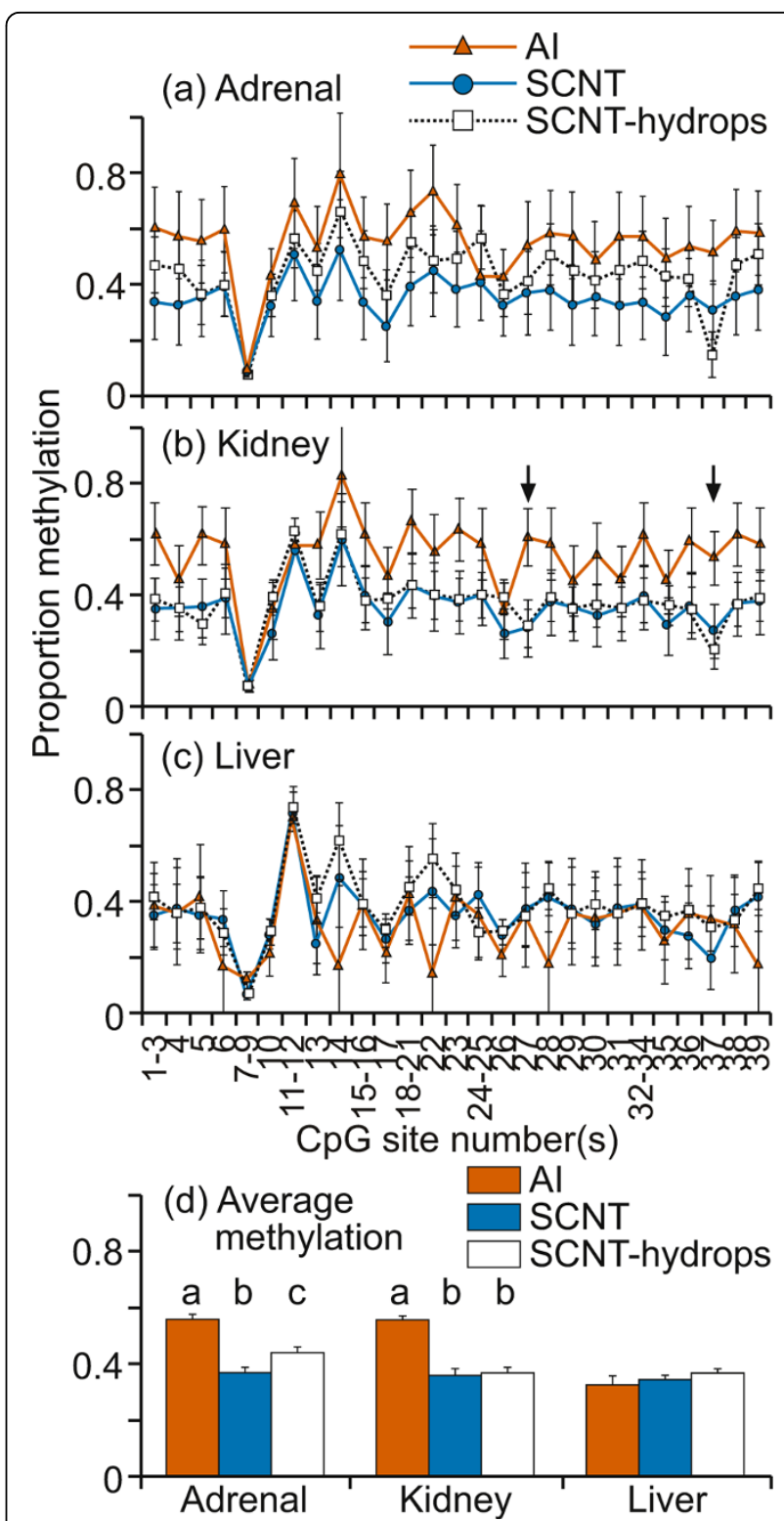

Figure 6 DNA methylation in the SNRPN exon 1 region Twenty-seven cleavage fragments that contained all $39 \mathrm{CpG}$ sites in the region were analyzed. The groups of cleavage fragments containing CpG sites 4, 29 and 31; 10 and 26; 15-16 and 32-34 could not be distinguished from each other in the analysis. Therefore, the proportion of methylation in each of these fragment groups is represented as an average value.

analysed. To eliminate the possibility that this was due to unknown SNPs resulting in a $\mathrm{C}$ to $\mathrm{T}$ conversion and thus loss of CpG sites, a subset of 10 DNA samples were amplified across this region and the amplicons sequenced. All samples contained the expected CGCGCG sequence.

\section{KCNQ10T1}

The KCNQ1OT1 region examined corresponds to the Kcnq1ot1 DMR in the mouse and human genomes. 
Similar to the above SNRPN region, the variation in methylation levels between individuals at each CpG site was large for all three tissues (figure 7). DNA from SCNT and SCNT-hydrops foetuses tended to be less methylated in all three organs when compared with AI samples, resulting in significantly lower regional average methylation (figure 7d) in the SCNT and SCNT-hydrops groups $(\mathrm{P}<0.001$, except the liver, where AI vs. SCNT, $\mathrm{P}=0.03)$. There was no significant difference between the SCNT and SCNT-hydrops groups. Where significant differences were detected between treatment groups at individual $\mathrm{CpG}$ sites (figure $7 \mathrm{a}$ and $7 \mathrm{~b}$ ), these differences were large compared with the differences seen in CDKN1C and KCNQ1.

$\mathrm{DIO} 3$

The DIO3 region examined is a good example of how widely DNA methylation levels at individual CpG sites/ fragments can vary within a single CpG island (20$100 \%)$. Highly methylated CpG sites appeared to be interspersed between $\mathrm{CpG}$ sites that were methylated at low levels (figure 8); this variation was seen in all three tissues and in all treatment groups. Only one CpG site in liver samples showed significant difference among the groups (figure 8c). There were no significant differences among the treatment groups (figure 8d) in regional average DNA methylation.

\section{Non-imprinted genes}

GR

Methylation levels in this region were relatively low (0$30 \%$ in the kidney and adrenal and $0-50 \%$ in the liver) at individual CpG sites (figure 9). Significant difference was found only in the kidney at once CpG site (figure 9b). There were no obvious tissue-specific methylation patterns. The mean regional methylation levels were 10 $15 \%$ with no difference detected among the treatment groups in any of the tissues (figure 9d).

\section{CSF-1}

Mean methylation levels were relatively low across the region analyzed (0-30\%) with little variation between individual CpG sites (figure 10) and no tissue-specific methylation patterns were evident. Although mean regional methylation levels were not different among the groups (figure 10d) there were specific CpG sites where significant differences were detected. These specific CpG sites were different for each tissue type (figure 10a, b, c). In all cases, the differences were small.

\section{DKK-1}

Mean methylation levels were similar to those reported for Day 26 trophoblast tissue [39], with all CpG sites methylated to $\sim 10 \%$, the exception being CpG31, where mean methylation levels were $40-50 \%$. There were no significant differences among the three groups.
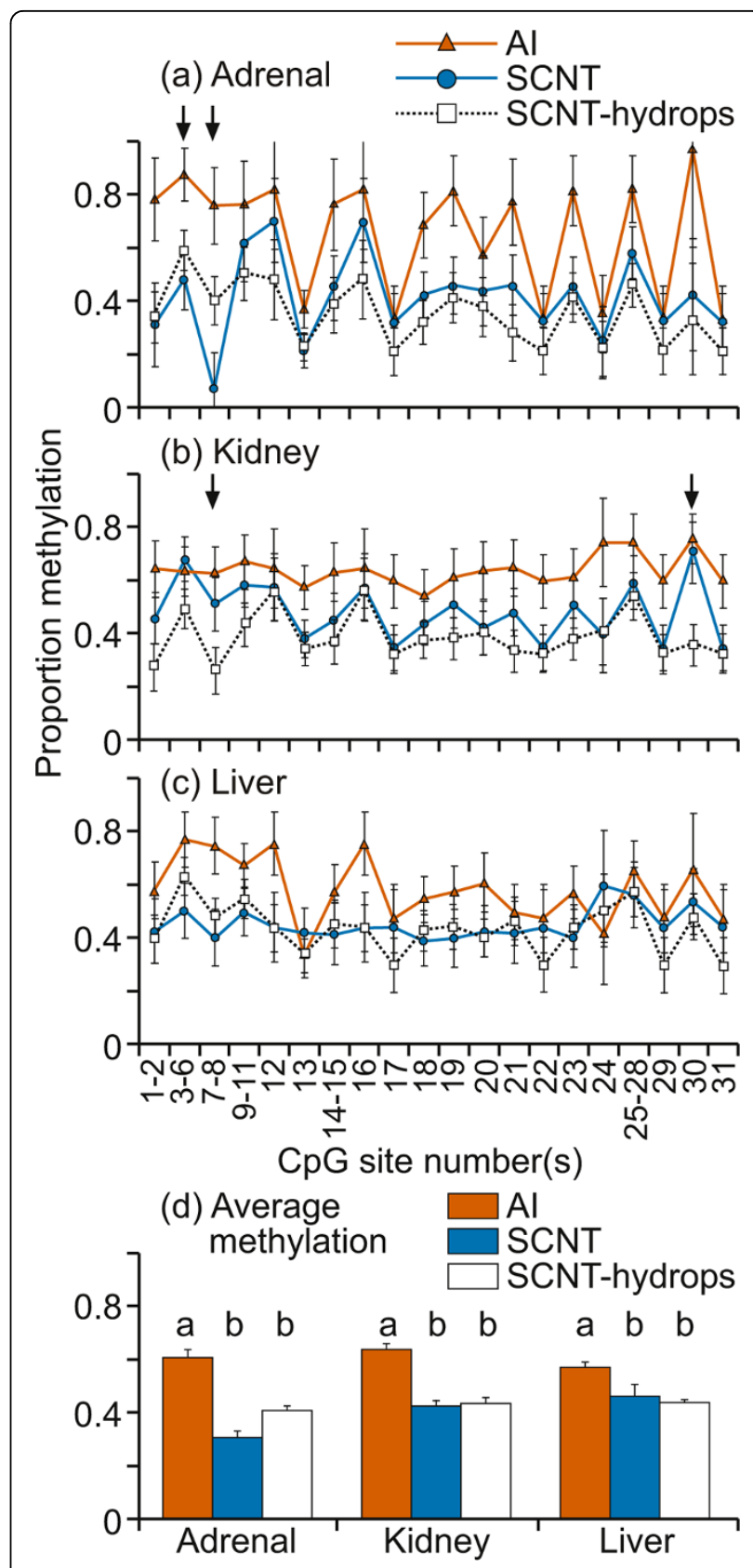

Figure 7 DNA methylation at the putative KCNQ1OT1 DMR Twenty cleavage fragments that contained all $31 \mathrm{CpG}$ sites in the region were analyzed. The groups of cleavage fragments containing CpG sites 12 and 16; 17 and 22 and 29 and 31; 19 and 23, could not be distinguished from each other in the analysis. Therefore, the proportion of methylation in each of these fragment groups is represented as an average value.

\section{STAT5a}

DNA methylation levels in a CpG island between STAT5a and STAT5b were mostly below 30\% in kidney, adrenal and liver samples (figure 11). The only difference between treatment groups was at one CpG site in 


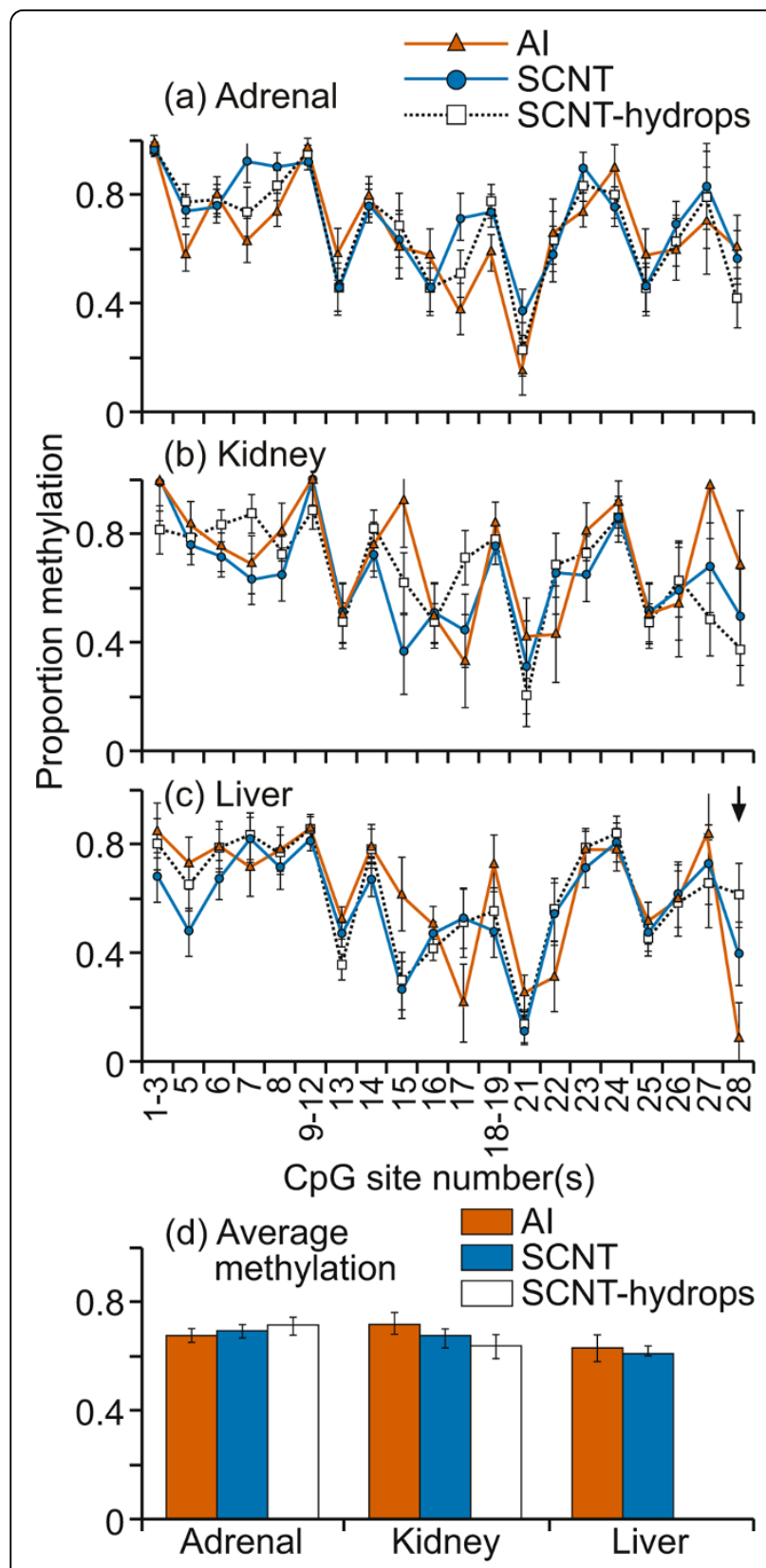

Figure 8 DNA methylation at the DIO3 polyA signal. Twenty cleavage fragments containing 26 out of a total of $28 \mathrm{CpG}$ sites in this region could be analyzed.

the liver samples (figure 11c). Individual methylation profiles of liver samples in the SCNT-hydrops group were more variable than those in the AI or SCNT groups with some $\mathrm{CpG}$ sites in certain individuals almost completely methylated. No differences were noted between the groups in the mean DNA methylation levels across the region in any of the tissues (figure 11d).

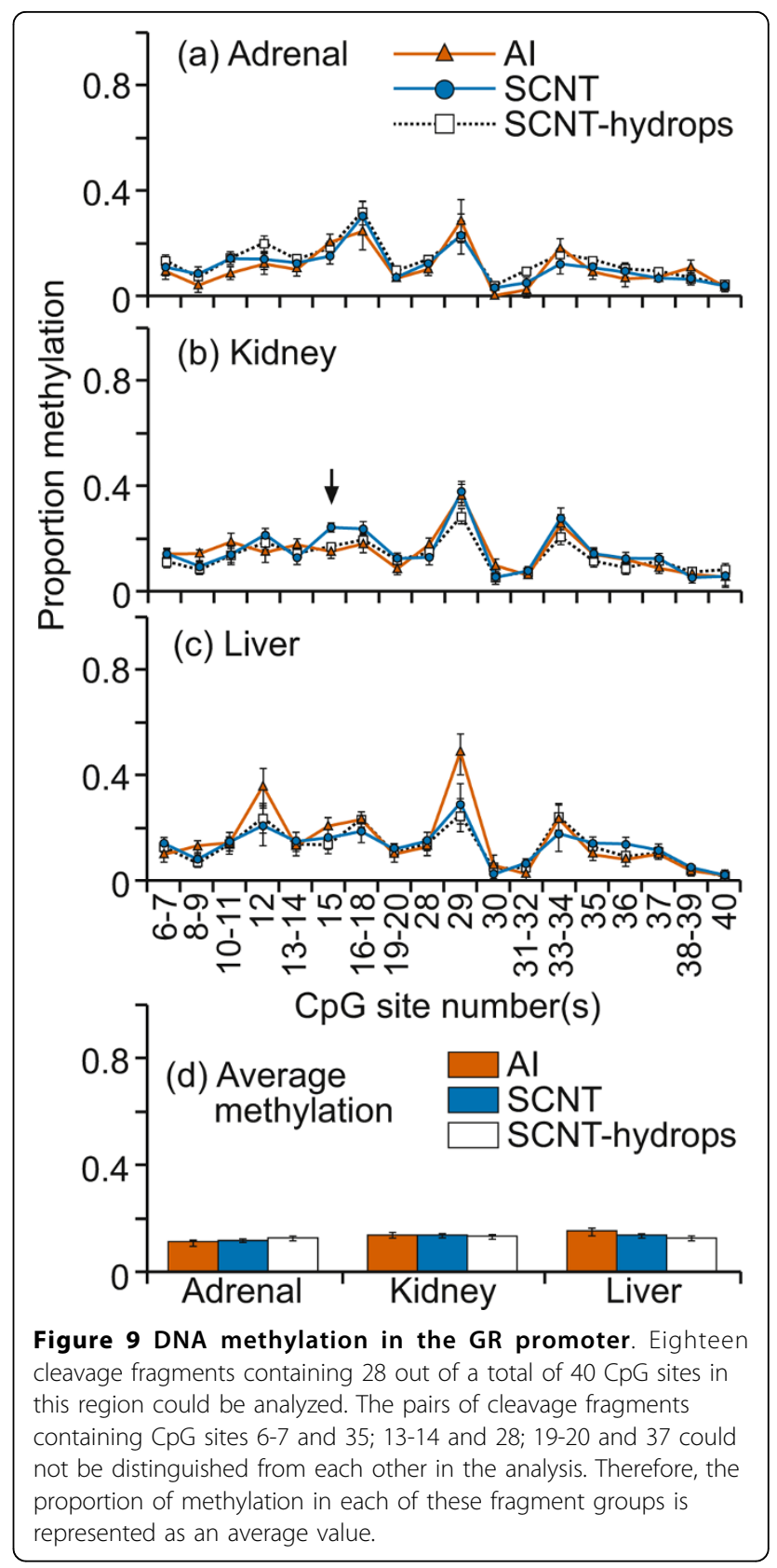

\section{Repeat regions}

\section{DNA Satellites I, II and alpha}

The majority of $\mathrm{CpG}$ sites in the Satellite I sequence examined were methylated to $>80 \%$ in all adrenal, kidney and liver samples (figure 12). Four of the CpG sites $(1,14,17$, and 22$)$ were consistently methylated to $\leq 50 \%$ in all tissue types. CpG sites where the mean methylation levels were significantly different among the groups were observed in all three tissues types (figure 12a, b, c). 


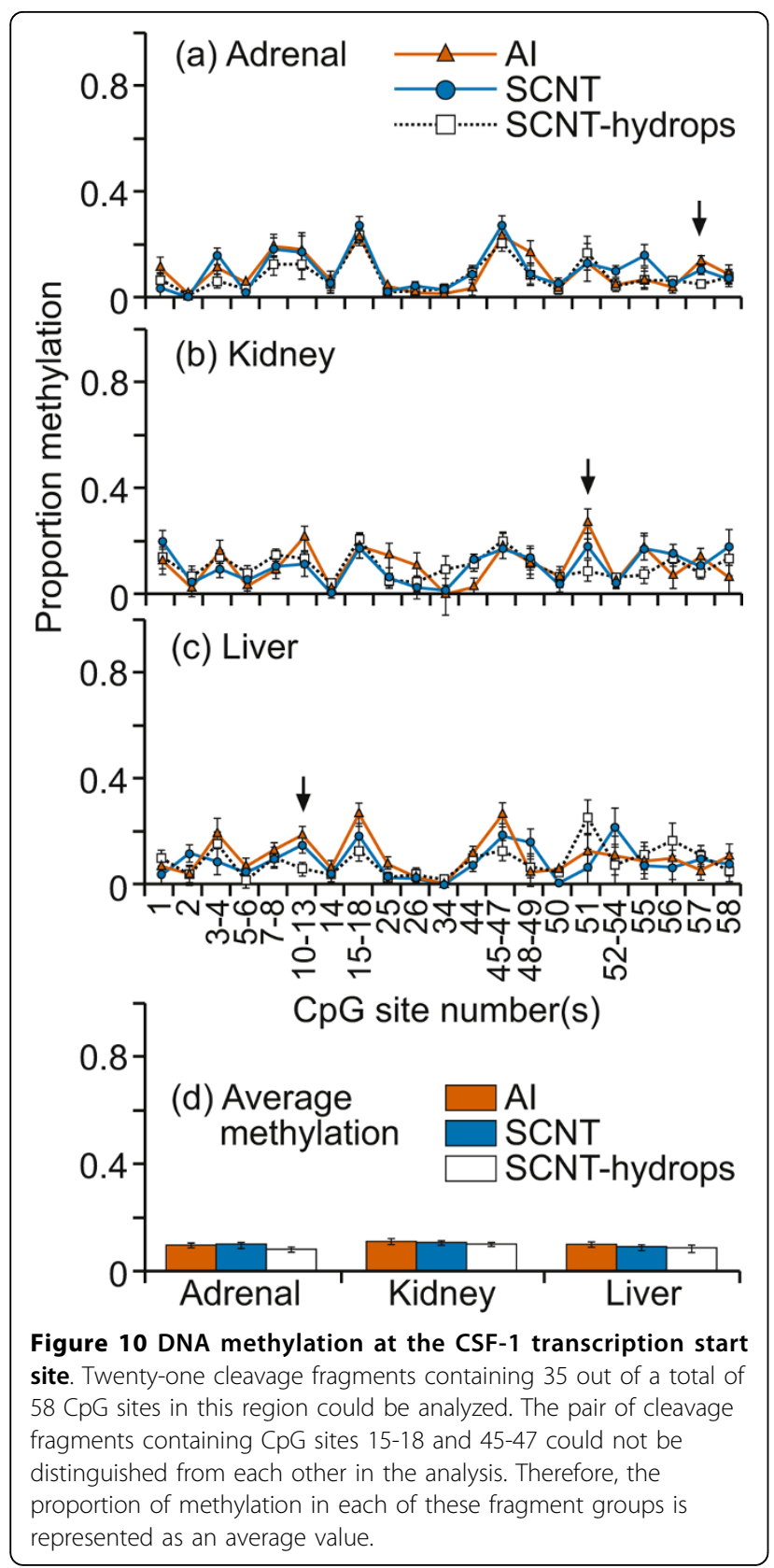

The methylation levels and pattern for Satellite II sequences were remarkably similar between individuals, treatment groups and tissue types (figure 13). CpG1 was invariably $100 \%$ methylated, CpG17 was methylated to 30-40\%. All other CpG sites were 70-80\% methylated. Only three cleavage fragments in SCNT kidney samples showed significantly different mean methylation levels compared with the other two groups (figure 13b).

The Satellite alpha sequences also showed similar patterns of methylation in all the treatment groups and

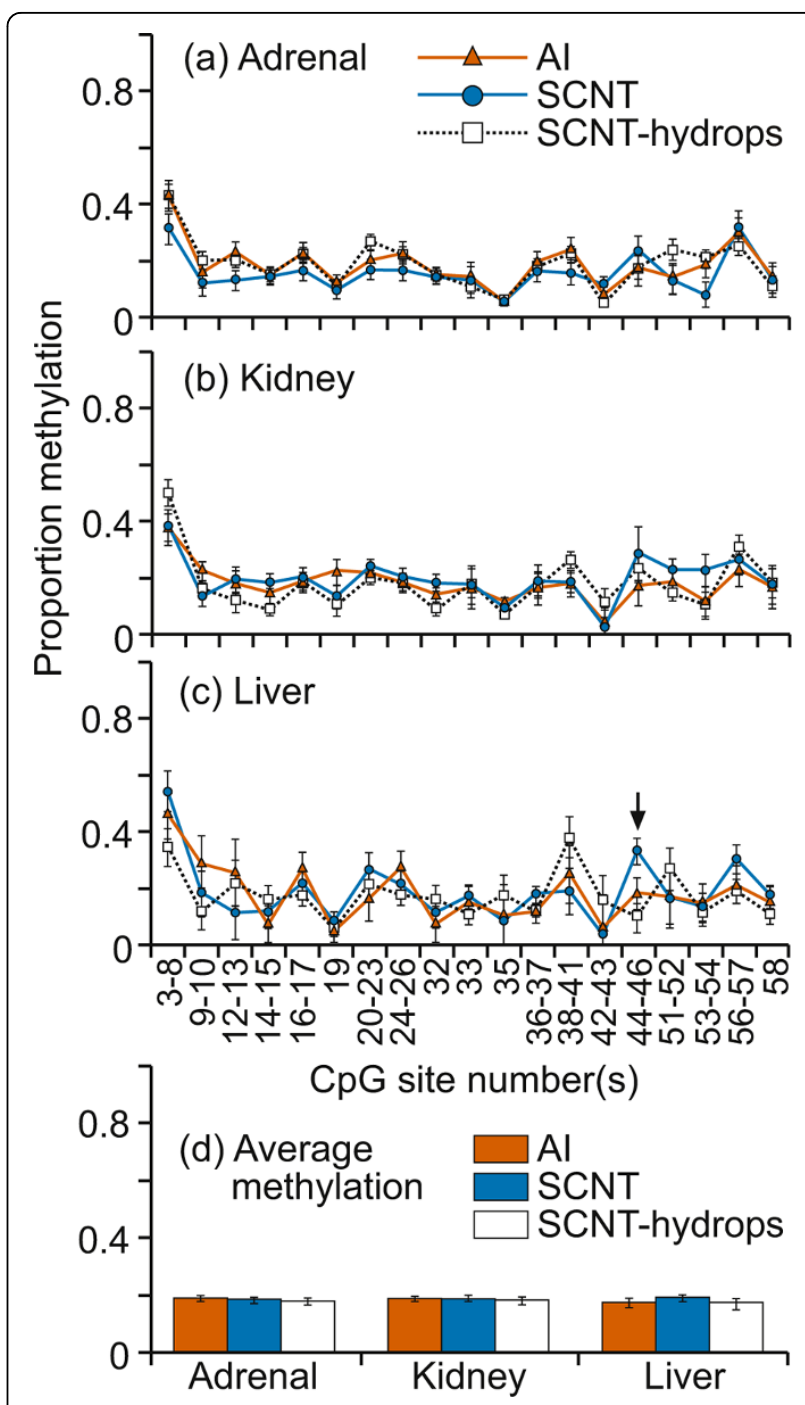

Figure 11 DNA methylation $10 \mathrm{~kb}$ upstream of the STAT5a transcription start site. Nineteen cleavage fragments containing 43 out of a total of $58 \mathrm{CpG}$ sites in this region could be analyzed. The pairs of cleavage fragments containing CpG sites $14-15$ and 32; 16-17 and 24-26; 33 and 58 could not be distinguished from each other in the analysis. Therefore, the proportion of CpGs methylated in each of these fragment pairs is represented as average values.

tissues (figure 14) with the only significant difference being found at one CpG site in the kidney (figure 14b). There were no apparent tissue-specific methylation patterns. Other than $\mathrm{CpG10}$, which showed a moderate level of variation between individuals, the other CpG sites were consistently methylated to the same degree in every sample, tissue and treatment group. CpG 13 was completely methylated in every sample. No significant differences were noted between the three groups in the mean DNA methylation levels across any of the 


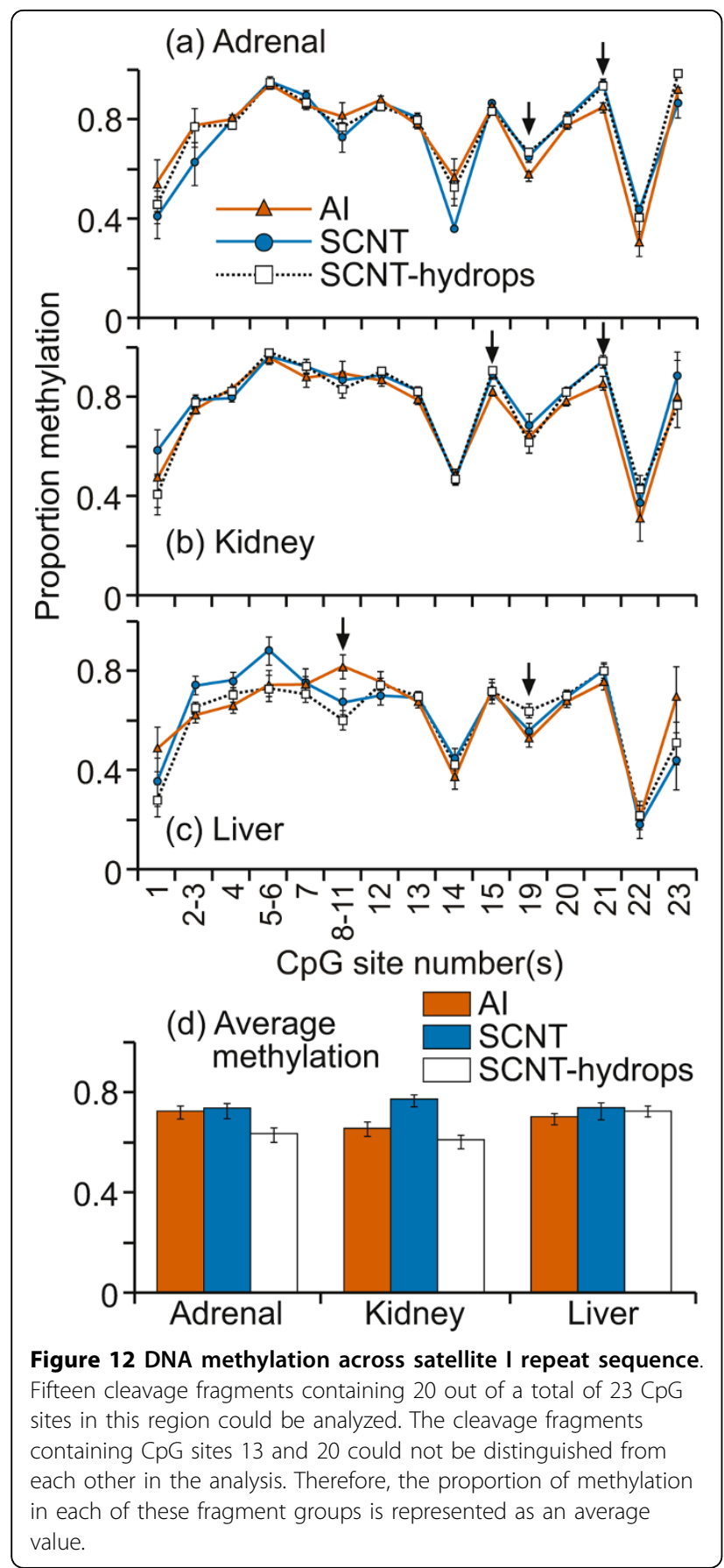

satellite regions in any of the tissues (figures 12d, 13d and $14 \mathrm{~d})$.

\section{Discussion}

In this study, we addressed the question of whether nuclear reprogramming has occurred appropriately after SCNT by examining DNA methylation patterns in tissue samples collected from three organs from mid-gestation foetuses. Being able to sub-divide the SCNT group into

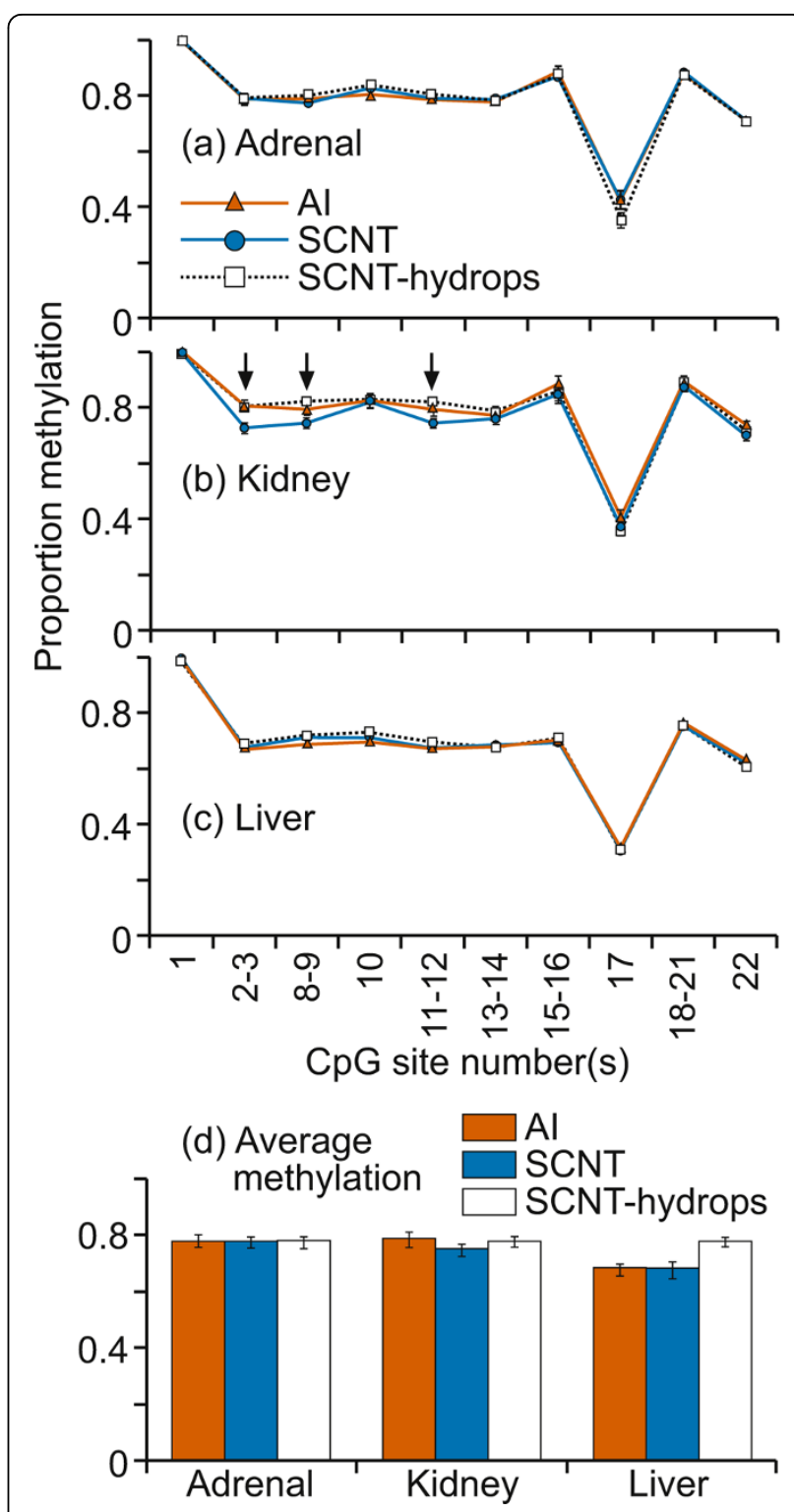

Figure 13 DNA methylation across satellite II repeat sequence. Ten cleavage fragments containing 18 out of a total of $22 \mathrm{CpG}$ sites in this region could be analyzed. The cleavage fragments containing CpG sites 8-9 and 11-12 could not be distinguished from each other in the analysis. Therefore, the proportion of methylation in each of these fragment groups is represented as an average value.

those that appeared "viable" at slaughter and those that were failing as a result of clinical hydrops (SCNThydrops) allowed us to determine if the failing foetuses were methylated differently compared with those that had the potential to develop further. As there are no means to determine, with certainty, the outcome from a foetus that looked "viable" at mid-gestation (SCNT or AI), we can only make the assumption that these SCNT foetuses have the potential, like the AI foetuses, to develop further. Previous studies have indicated that 


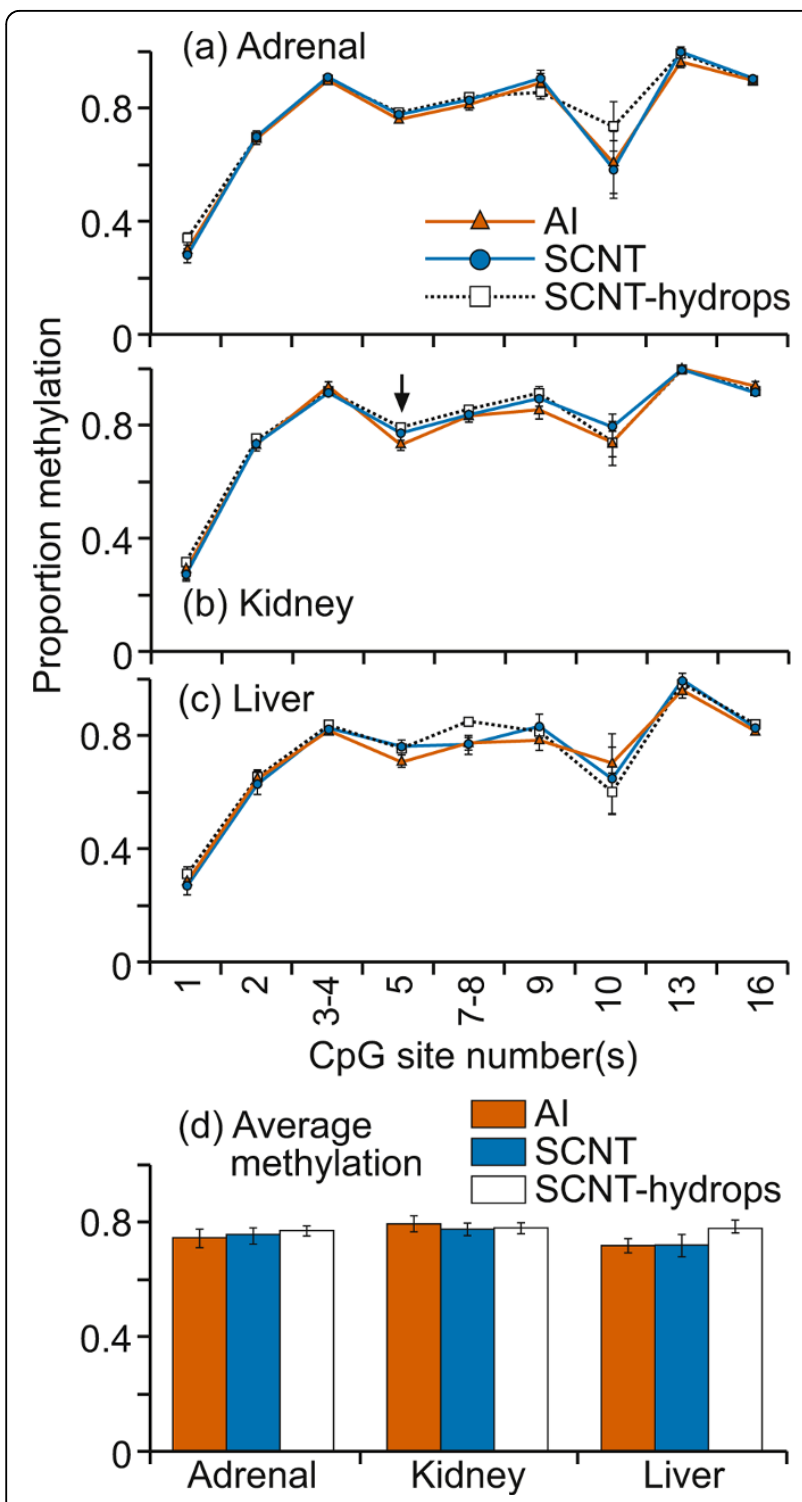

Figure 14 DNA methylation across satellite alpha repeat sequence. Nine cleavage fragments containing 11 out of a total of $16 \mathrm{CpG}$ sites in this region could be analyzed. The cleavage fragments containing $\mathrm{CpG}$ sites 3-4 and 16 could not be distinguished from each other in the analysis. Therefore, the proportion of methylation in each of these fragment groups is represented as an average value.

$50-75 \%$ of foetuses surviving to mid-gestation will result in a live calf [40-43]. In the majority of regions examined, the DNA from the SCNT or SCNT-hydrops samples were appropriately methylated when compared with control AI samples. Generally, there were no differences in the mean methylation patterns and levels between the SCNT and SCNT-hydrops groups despite evident phenotypic differences. However, close inspection of individual profiles revealed that within the SCNT-hydrops group, there were individuals who showed aberrant hypo- or hypermethylation, particularly in the IGF2 exon 10 DMR, KCNQ1OT1, SNRPN and HAND1 regions. Aberrant methylation in any of those genes was not always accompanied by aberrant methylation in other regions. Furthermore, two individual that are genetically identical could be aberrantly methylated in different ways, demonstrating the stochasticity of the reprogramming defects. At specific CpG sites, significant differences between SCNT and AI samples were detected in some genes. It is not possible to say if these sites represent "hot-spots" for methylation variation or whether these methylation aberrations are the cause of some of the abnormal phenotype seen in SCNT foetuses.

Genes in the BWS locus were of particular interest because of the variable overgrowth phenotypes seen in SCNT foetuses and how some of the phenotypes resemble BWS in humans. The methylation profiles of $\mathrm{CpG}$ islands associated with the KCNQ1 and CDKN1C genes were practically identical between the AI control and both groups of SCNT, in liver, kidney and adrenal samples. This suggests that the methylation at these sites is tightly regulated and they were appropriately methylated in these SCNT organs, even in those from failing hydrops pregnancies. Similarly, no differences were observed for the region associated with ASCL2. This tight regulation did not extend to the KCNQ1OT1 region located close to the CDKN1C gene in this imprinted cluster. CpG sites in the KCNQ1OT1 region showed substantial variation between individuals and a tendency for SCNT samples to be less methylated at almost every analyzable $\mathrm{CpG}$ site. Taken together, these results suggest that even within the same locus, some CpG islands are methylated appropriately in SCNT tissues while others are less so. As it was not possible to distinguish between the maternal and paternal allele in cattle, we were unable to determine if the aberrant methylation was restricted to one allele or if both were aberrantly methylated.

Similarly, at the region corresponding to the SNRPN imprint control region in humans, the methylation levels were also highly variable between individuals in all groups. Mean methylation at the majority of $\mathrm{CpG}$ sites in both SCNT groups tended to be lower when compared with the AI group, although not as dramatically hypomethylated as in early extraembryonic tissues, (Couldrey and Lee, unpublished data and that of others [25]). Although there was a tendency for this region to be incorrectly methylated following SCNT, not all CpG sites in this region were affected in the same way. An example of this is the cleavage fragment containing CpG7-9 which was consistently unmethylated for every sample in each of the three tissues in all treatment groups. It is possible that these $\mathrm{CpG}$ sites are invariably protected from epigenetic modification. 
Small but statistically significant differences in methylation levels between SCNT and the control group were detected at specific CpG sites in HAND1, ASCL2 and the KCNQ1 promoter regions in various tissues. These differences were very small and the overall methylation status of the entire region examined was not altered so their biological significance is uncertain. The occurrence of these very small differences is no higher than would be expected purely by chance at the $5 \%$ level. Only the HAND1 region showed tissue specific methylation differences as the adrenal tissues have a noticeably different pattern compared with the other two tissues. In these regions, the similarity in methylation pattern between $\mathrm{SCNT}$ and normal tissues suggests that this region has undergone appropriate reprogramming and that tissuespecific methylation patterns were successfully established in this organ. Where there were no tissue-specific methylation differences, the absence of difference in methylation between AI and SCNT samples is either an indication of successful reprogramming or that these regions normally escape global demethylation $[23,29,44]$ in the pre-implantation embryo and therefore did not require extensive reprogramming after SCNT.

For imprinted genes, the imprints that mark the parental origin of each allele are normally established during gametogenesis, leading to differential methylation of the male and female gametic DNA in DMRs. The methylation levels in DMRs have previously been reported to be $\sim 50 \%$. This level of methylation was believed to be due to the almost complete methylation of one parental allele versus the non-methylation of the other allele. We found that for the IGF2 exon 10 DMR, the majority of the CpG sites were methylated to between 70 to nearly $100 \%$ in the three foetal tissues examined, even in the controls. Assuming that the paternal allele was completely methylated, this suggests that the maternal allele was progressively methylated during development. One possible explanation for this is that after additional epigenetic marks that dictate allele-specific expression are established during early embryogenesis, there is no longer the requirement to maintain the differential marking at the DMRs so most of the CpG sites in somatic cells then become progressively methylated. Alternatively, it may be that only a few CpG sites in the region are required to be differentially methylated to distinguish the parental alleles so the non-essential sites become methylated through methylation spreading.

Comparison of the methylation profiles in nonimprinted genes and the repetitive DNA satellite regions showed that in general, these regions appeared to be appropriately methylated in the SCNT tissue samples examined. Although satellite sequences are non-coding and are thought to be kept highly methylated in the genome, not every CpG site was methylated to the same extent across the region. Despite significant differences in methylation levels at specific CpG sites between treatment groups, these differences are very small and the significance in unclear.

An intriguing observation from this study is that in some genes, there is a surprisingly large variation in the methylation levels between individuals at practically every $\mathrm{CpG}$ site in the region examined, even between individuals in the normal control group. This suggests that there is tolerance for a range of DNA methylation levels in some genomic regions; whether this translates to phenotypic variability is unknown. This variability could be in part, explained by the inherent lower fidelity (compared with DNA replication) of the DNA maintenance methylation mechanism, which is estimated to be about $95 \%$ for methylation of the newly unmethylated strand [45]. However, this does not explain why the methylation of certain regions is so tightly regulated. This variability is not due to heterogeneous tissue sampling as the analyses for multiple genes were carried out on the same bisulfite-treated DNA sample for each individual. In these same samples, other genomic regions showed very tight invariant methylation at almost all CpG sites in every individual. In general, consistent with previous findings [45] CpG islands upstream of transcriptional start sites or near promoters were less methylated (5-20\%) than the two putative DMRs and satellite sequences, which tended to be methylated to 40-100\%.

Previous studies assessing the reprogramming of the donor nucleus after SCNT have used antibodies raised against methylcytosine residues to compare global methylation in the nuclei of SCNT and normal embryos [27]. This technique only allows visualization of highly methylated regions which are likely to be repeat sequences that do not code for functional genes. Subtle differences in regions present at two copies per genome will be masked by the overall methylation of highly repetitive elements. Other techniques which average DNA methylation levels over the genomic region analyzed have led to the misconception that DNA methylation levels are similar at each $\mathrm{CpG}$ site across the entire CpG island. In contrast, the MassARRAY technology is able, in many instances, to calculate DNA methylation levels at individual $\mathrm{CpG}$ sites reproducibly down to 5\% for each informative CpG unit [38]. However, because the MassARRAY method depends on sequence-specific cleavage of derived RNA products, this technology is unable to analyze the methylation at every $\mathrm{CpG}$ site when suitable cleavage sites are unavailable such as in high density CpG regions. Bisulfite sequencing will be a useful adjunct when these regions warrant further examination. The success of both techniques however, is dependent on being able to design primers that flank 
500 bp of CpG-rich sequences but the primers themselves must bind to regions which do not contain $\mathrm{CpG}$ sites. For some $\mathrm{CpG}$ islands that are large (up to $\sim 8 \mathrm{~kb}$ ), this is not always possible and other methods must be devised to study such regions.

The ability to analyze large numbers of samples and genes and quantify the level of methylation at specific CpG sites allows a more accurate assessment of methylation profiles in the populations of interest. The technology has enabled us to appreciate detail previously unrealized: a) some $\mathrm{CpG}$ sites are always protected from methylation whilst others tend to be highly methylated; b) methylation at some CpG site(s) within a region show high variability between individuals whilst others are invariably methylated in every individual; c) some regions, such as the KCNQ1OT1 site in adrenal tissues and DIO3 in all tissues show apparent periodicity in the methylation profile, with highly-methylated sites interspersed with lowly-methylated sites; d) tissue-specific methylation patterns were uncommon. It remains for the biological significance of these observations to be determined.

The detail revealed by this method of DNA methylation analysis calls into question whether the practice of reporting the average methylation level across all CpG sites within a region and comparing this value between experimental samples is meaningful. This could potentially mask methylation differences between experimental groups at CpG sites that may be important for regulating chromatin structure and hence, gene expression. CpG sites that are invariably protected from methylation, or those which are always methylated are not evident when averaging methylation levels across a region. Subtle tissue-specific differences may also be masked. Furthermore, the biological significance of averaged methylation levels in a region is unclear.

\section{Conclusions}

We have used the MassARRAY technology to look at multiple regions in the genome and found that for SCNT foetuses that survived to mid-gestation, albeit with phenotypic abnormalities in some cases, the methylation patterns were very similar to those of naturally conceived foetuses, at least for the three organs examined. This suggests that in those foetuses, the majority of these sites in the genome have been appropriately "reprogrammed". However, there were two regions located in imprinted gene clusters (BWS and PWS loci) where SCNT samples tended to be hypomethylated. This implies the importance of these two region in regulating normal foetal development and growth. Similar observations of aberrant methylation in the BWS locus in children arising from human IVF is further evidence of the susceptibility of this region to external influence.
We cannot yet with confidence predict the developmental outcome of a SCNT foetus from its epigenetic state at any stage; it is just a snap-shot of the dynamic nature of the epigenetic status of the genome. We are far from understanding how DNA methylation patterns relate to phenotypic outcomes in entire organisms.

\section{Methods}

\section{Production and collection of foetal tissues}

All manipulations of animals involved in the present study were conducted in accordance with the regulations of the New Zealand Animal Welfare Act of 1999. SCNT embryos were produced essentially as previously described [40]. An adult skin fibroblast cell line (AESF-1) from a high genetic merit Friesian bull was used as nuclear donor. After in vitro culture for 7 days, the embryos were transferred to synchronized recipients and pregnancy establishment determined at Day 35 of gestation by trans-rectal ultrasound scanning. Pregnancies were monitored monthly by ultrasound scanning until Day 120. From then, the animals were monitored closely by rectal palpation for the development of hydrallantois. SCNT pregnancies that were diagnosed with hydrops were terminated by slaughter at the abattoir. Viable SCNT pregnancies from the same cohort but without hydrops were also terminated at around the same gestation as those with hydrops. Additional samples from SCNT-hydrops pregnancies at similar stages of gestation generated from several other donor cell lines were included in the study. Thus, the group SCNT-hydrops consisted of SCNT foetuses derived from the AESF-1 line as well as from five other cell lines of both sexes and of different breeds. This allowed us to investigate whether the DNA methylation status is similar or different in SCNT-hydrops foetuses with different genetic backgrounds. Control pregnancies were generated by artificial insemination (AI) with frozen semen from the bull which provided the AESF-1 donor cells and foetal tissues were collected at the equivalent stage of gestation as the SCNT foetuses. The uteri and its contents were recovered after slaughter of the recipient dams. Gross foetal and placental morphology was recorded and foetal and placental tissue samples collected and snap-frozen in liquid nitrogen. For this study, three organs, the kidney, liver and adrenal glands, which commonly show growth disregulation in SCNT foetuses, were used (AI, $\mathrm{n}=5$; SCNT, $\mathrm{n}=6$ and SCNT-hydrops, $\mathrm{n}=4$ from the AESF- 1 line and $\mathrm{n}=6$ from other cell lines).

\section{Identification of $\mathrm{CpG}$ islands for analysis}

Promoter regions (up to $10 \mathrm{~kb}$ upstream of the putative transcription start site) and transcribed regions of selected genes were analysed for the presence of $\mathrm{CpG}$ 
islands (observed/expected $\mathrm{CpG}$ dinucleotide ratio of $>0.60, \mathrm{C}+\mathrm{G}$ content $>50 \%$, length $>200 \mathrm{bp}$ ) using Emboss on EBI website.

Primers were designed (table 1), using MethPrimer, to flank and amplify $\mathrm{CpG}$ island sequences in genes of interest, as described [46]. Primer sequences contained at least four Cs that were not in $\mathrm{CpG}$ pairs and no $\mathrm{CpG}$ sites. The regions of interest chosen include: a) a region spanning the putative transcription start site of ASCL2, a gene associated with placental development; b) a region in exon 10 of IGF2 (GenBank accession no. X53553) that is differentially methylated [47]; c) a region spanning the putative transcription start site of KCNQ1; d) $500 \mathrm{bp}$ of the $\mathrm{CpG}$ island corresponding to the human KCNQ1OT1 DMR; e) 1-0.5 kb upstream of exon 1 of HAND1, coding for a transcription factor associated with trophoblast differentiation, cardiogenesis and the development of neural crest derivatives; f) part of exons 3 and 4 and intron 3 of CDKN1C; g) a region beginning upstream of exon 1 , covering exon 1 and part of intron 1 of SNRPN (GenBank accession no. AY743660); h) a region at the transcriptional start site for the DIO3 antisense transcript, covering the polyA signal of DIO3 gene, which codes for iodothyronine

Table 1 PCR primers used for Sequenom analysis

\begin{tabular}{|c|c|c|c|}
\hline Name & Sequence & Chromosomal location & Product size (bp) \\
\hline SNRPN_L & AGGAAGAGAGTTGGGAGGTATTATTTTGGGTTGAA & ChrU:24360-23919 & 437 \\
\hline SNRPN_R & CAGTAATACGACTCACTATAGGGAGAAGGCTAACCCCAAACCTCCAAAAATTATC & & \\
\hline$\overline{\text { IGF2_L }}$ & AGGAAGAGAGGGGTATTTGGGGTAGTTTAGG & Chr29:3633319-3633749 & 521 \\
\hline$\overline{\text { IGF2_R }}$ & CAGTAATACGACTCACTATAGGGAGAAGGCTATTCTAATCCCCTCAACCAAATAAA & & \\
\hline$\overline{C D K N 1 C \_L}$ & AGGAAGAGAGGTAGTGGTATATTAAGTTGGAAGTTGTAGT & Chr29:2954381-2953897 & 485 \\
\hline$\overline{C D K N 1 C \_R}$ & CAGTAATACGACTCACTATAGGGAGAAGGCTTAGTTAGGTTAGAGTTAGTT & & \\
\hline HAND1_L & AGGAAGAGAGGAGAAAGGTTITGGGGATAAAATT & Chr7:1101938-1101390 & 549 \\
\hline HAND1_R & CAGTAATACGACTCACTATAGGGAGAAGGCTCAAACCCTACAACTAACAAAACATCC & & \\
\hline$\overline{\mathrm{ASCL} 2 \_\mathrm{L}}$ & AGGAAGAGAGGTATTAGGGGGAGTTTGGTAG & Chr29:3526331-3526685 & 354 \\
\hline$\overline{A S C L 2 \_R}$ & CAGTAATACGACTCACTATAGGGAGAAGGCTCTAAAACCCCAAATTCACCAACTTC & & \\
\hline$\overline{\text { KCNQ1_L }}$ & AGGAAGAGAGGGGTTGGTTAAGAAGTGTTाTाTा & Chr29:3365714-3365215 & 500 \\
\hline KCNQ1_R & CAGTAATACGACTCACTATAGGGAGAAGGCTAATCAAACCCACAAAACCCTAAACTT & & \\
\hline Dio3_L & AGGAAGAGAGTTTGTATTTGTTTGGTTTGTTTAA & Chr21:1453786-1454238 & 453 \\
\hline Dio3_R & CAGTAATACGACTCACTATAGGGAGAAGGCTCAACTCTTCATCAACAATAAAACTC & & \\
\hline KCNQ1OT1_L & AGGAAGAGAGTAGTTGATTGGATAGTTTGTAGGGG & Chr29:3133697-3133352 & 346 \\
\hline KCNQ1OT1_R & CAGTAATACGACTCACTATAGGGAGAAGGCTCCACAAATATTCCTCAAAATCACTC & & \\
\hline STAT5_L & AGGAAGAGAGTTTGTAGAGGTAGTTGATTTTTGAGGA & Chr19:872990-873467 & 478 \\
\hline$\overline{\text { STAT5_R }}$ & CAGTAATACGACTCACTATAGGGAGAAGGCTAAAAAAACAAAACACTCCCTCTCTC & & \\
\hline$\overline{G R \_R}$ & CAGTAATACGACTCACTATAGGGAGAAGGCTAATTITCTCTATAATTTCTCTTCTTACC & Chr7: 2747426-2747103 & 324 \\
\hline$\overline{G R \_L}$ & AGGAAGAGAGTTITITTAAGTTITITAGAGGG & & \\
\hline$\overline{\text { DKK_001_L }}$ & AGGAAGAGAGTTTITITGAGTTITITGAGATGA & Chr26:336954-336488 & 467 \\
\hline$\overline{\text { DKK_001_R }}$ & CAGTAATACGACTCACTATAGGGAGAAGGCTCACTTAAACACCCAATACCACACT & & \\
\hline$\overline{\text { DKK_002_L }}$ & AGGAAGAGAGGTGTGGTATTGGGTGTTTAAGTGT & Chr26: 336510-336157 & 534 \\
\hline$\overline{\text { DKK_O02_R }}$ & CAGTAATACGACTCACTATAGGGAGAAGGCTCCTAAAATCCTTTCTAAAAATCCTC & & \\
\hline$\overline{\text { CSF-1_L }}$ & AGGAAGAGAGGTAGTTITGGAGTAGTTGTAGGGT & Chr3: 629601-630161 & 561 \\
\hline$\overline{\text { CSF-1_R }}$ & CAGTAATACGACTCACTATAGGGAGAAGGCTCAAAATAATTTCCCATAAACCACATAC & & \\
\hline Satellite I_L & AGGAAGAGAGTGTAGATTGGGGATAGGAGAGTTAG & N/A & 345 \\
\hline Satellite I_R & CAGTAATACGACTCACTATAGGGAGAAGGCTCCTACTTTATCTAAAAAAAATTACCTTCC & & \\
\hline Satellite II_L & AGGAAGAGAGTTTGGTTTAAGGTTGGGAGTTTAAAG & N/A & 278 \\
\hline Satellite II_R & CAGTAATACGACTCACTATAGGGAGAAGGCTAAAACAACAATCAAACACCACTCAC & & \\
\hline Satellite alpha_L & AGGAAGAGAGTTITITTGATTTGGATAGGAGGG & N/A & 279 \\
\hline Satellite alpha_R & CAGTAATACGACTCACTATAGGGAGAAGGCTACTATATTTAAAACCAAAAATTTTCC & & \\
\hline
\end{tabular}


deiodinase type 3; i) a CpG island (covered by two nonoverlapping amplicons) at the transcriptional start site of DKK-1, a potent inhibitor of the WNT signalling pathway which is highly expressed in mesenchymal lineages and may mediate the inductive interactions between the mesenchyme and the epithelium; $j$ ) a region $10 \mathrm{~kb}$ upstream of the transcriptional start site of STAT5a, a signaling protein for many cytokines and growth factors; k) a region in the bovine GR gene equivalent to the rat exon $1_{7}$ promoter region, previously shown to be epigenetically modified in rat pups by maternal behaviour towards them [48-50]; 1) a region near the transcriptional start site of CSF-1, a cytokine implicated in the development of certain haematopoietic cell lineages; $\mathrm{m}$ ) a region spanning a $\mathrm{CpG}$ island in satellite sequence I (GenBank accession no. J00032); n) a region spanning a $\mathrm{CpG}$ island in satellite sequence II (GenBank accession no. X03116); and o) a region spanning a CpG island in satellite sequence alpha (GenBank accession no. AJ293510). The regions chosen for KCNQ1OT1, GR, IGF2 exon 10 DMR, and SNRPN were those where DNA methylation had previously been analyzed in the human, mouse, rat or cow. For ASCL2, KCNQ1, DIO3, DKK1 and CSF1, where there have been no previous data, we chose to analyze DNA methylation in CpG islands near the transcription start sites. Due to the high $\mathrm{C}+\mathrm{G}$ content and density of $\mathrm{CpG}$ sites in the CDKN1C gene, it was not possible to design primers that could be used with bisulfite-converted DNA that would span $<500 \mathrm{bp}$ in the promoter region. The intragenic region analyzed in CDKN1C was as close to the promoter as possible.

\section{DNA extraction}

Tissues were ground up in liquid nitrogen to a powder to ensure homogeneity for DNA sampling. Between 20 and $100 \mathrm{mg}$ of tissue was then used for DNA extraction using either phenol/chloroform [51] or a DNeasy kit following the manufacturer's protocol (Qiagen, Austin, TX). DNA concentration and purity was measured using the Nanodrop spectrophotometer (Thermo Scientific, DE, USA)

\section{Analysis of DNA methylation}

DNA samples were analyzed using the methods described $[38,52,53]$. Briefly, $1 \mu \mathrm{g}$ DNA was bisulfite treated using the EZ-96 DNA Methylation gold kit (Zymo, CA, USA) to produce methylation-dependent sequence variations of $\mathrm{C}$ to $\mathrm{T}$ and regions of interest were amplified using T7 tagged PCR primers. PCR conditions were: $200 \mathrm{nM}$ of forward and reverse primers, $200 \mu \mathrm{M}$ of each dNTP, 1× Qiagen HotStar buffer, 0.2 U Qiagen HotStar Taq polymerase and $2 \mu \mathrm{l}$ bisulfite converted DNA per reaction in a total volume of $10 \mu \mathrm{l}$. PCR cycling conditions were: $94^{\circ} \mathrm{C} 15 \mathrm{~min}$ followed by 45 cycles of $94^{\circ} \mathrm{C}, 20 \mathrm{sec} ; 56^{\circ} \mathrm{C}, 30 \mathrm{sec} ; 72^{\circ} \mathrm{C}, 1 \mathrm{~min}$ with a final extension at $72^{\circ} \mathrm{C}$ for $3 \mathrm{~min}$. PCR products were analyzed by agarose gel electrophoresis to confirm successful amplification. In vitro amplification and transcription was performed on the reverse strand using $2 \mu \mathrm{l}$ of PCR product using T7 DNA and RNA polymerases and a simultaneous $\mathrm{U}$ specific cleavage by RNAse A. Approximately $20 \mathrm{nl}$ of each sample was spotted onto Sequenom MassARRAY chips and subject to mass spectrometry. The efficiency of bisulfite conversion was determined by assessing the quality of the raw data. Incomplete bisulfite conversion generates mass peaks at a mass/charge ratio of $16,32,48$, etc. greater than the expected peaks, in addition to the expected peaks. Such data were infrequent and excluded from the analyses.

\section{Statistical analysis}

Spectra were analyzed using proprietary peak picking and signal-to-noise ratio calculations. The relative methylation of the $\mathrm{CpG}$ sites was then calculated (EpiTYPER, Sequenom, CA, USA) by dividing the peak intensity (area under the peak) of the fragment representing the original methylated DNA, by the sum of the intensities of the peaks representing both methylated and non-methylated DNA. Mean DNA methylation levels for each fragment were compared using the least significant differences calculated from the analysis of variance across the three treatment groups in each tissue examined. The mean methylation level across the region contained in the amplicon was also calculated for each gene and compared pair-wise between treatment groups for each tissue using the t-test. Results are presented as mean $+/$ - standard error of the mean (S.E.M).

\section{Note \\ DNA methylation levels at CpG sites in the amplicons}

Each CpG site or groups of sites which could be analyzed by Sequenom MassARRAY are arranged in the order that they appear in the DNA sequence, 5 ' to 3 ' on the $\mathrm{x}$-axis. Where there are more than one $\mathrm{CpG}$ sites in a fragment, the numbered $\mathrm{CpG}$ sites are grouped together in one position on the $\mathrm{x}$-axis and the proportion of methylation refers to the most methylated site (Sequenom EpiTYPER 1 software). The y-axis represents the proportion of methylation at specific $\mathrm{CpG}$ sites in the region analyzed. The error bars represent the SEM and arrows indicate $\mathrm{CpG}$ sites where there is significant difference $(P<0.05)$ among the treatment groups. a) adrenal, b) kidney and c) liver tissues, d) average methylation in the genomic region represented by the amplicon; columns with different labels are significantly different from each other $(\mathrm{P}<0.05)$. AI: AI controls; 
SCNT: SCNT samples from apparently viable foetuses; SCNT-hydrops: SCNT samples from foetuses terminated because of hydrops.

\section{Acknowledgements}

The authors would like to thank David Wells and cloning group for producing the SCNT embryos, Martin Berg for animal care and treatment, Tim Manley for the Sequenom MassARRAY sample analysis, Darryl Irwin from Sequenom for excellent technical support, Ning Li and Anita Ledgard for assisting with tissue collections, Neil Cox for statistical assistance, and Pauline Hunt for graphics assistance. This work was supported by a grant from the New Zealand Foundation for Research, Science, and Technology (C10X0303).

\section{Authors' contributions}

CC designed and carried out the DNA methylation studies and participated in the data analysis and drafting of the manuscript. RSFL conceived the study and generated the foetuses for the tissue collection, participated in data analysis and drafting of the manuscript. All authors read and approved the final manuscript.

Received: 19 August 2009 Accepted: 7 March 2010

Published: 7 March 2010

\section{References}

1. Wilmut I, Schnieke AE, McWhir J, Kind AJ, Campbell KH: Viable offspring derived from fetal and adult mammalian cells. Nature 1997, 385(6619):810-813.

2. Wells DN, Misica PM, Day AM, Peterson AJ, Tervit HR: Cloning sheep from cultured embryonic cells. Reproduction, Fertility, \& Development 1998, 10(7-8):615-626.

3. Hill JR, Burghardt RC, Jones K, Long CR, Looney CR, Shin T, Spencer TE, Thompson JA, Winger QA, Westhusin ME: Evidence for placental abnormality as the major cause of mortality in first-trimester somatic cell cloned bovine fetuses. Biol Reprod 2000, 63(6):1787-1794.

4. Hill JR, Edwards JF, Sawyer N, Blackwell C, Cibelli JB: Placental anomalies in a viable cloned calf. Cloning 2001, 3(2):83-88.

5. De Sousa PA, King T, Harkness L, Young LE, Walker SK, Wilmut I: Evaluation of gestational deficiencies in cloned sheep fetuses and placentae. Biol Reprod 2001, 65(1):23-30

6. Heyman Y, Chavatte-Palmer P, LeBourhis D, Camous S, Vignon X, Renard JP: Frequency and occurrence of late-gestation losses from cattle cloned embryos. Biol Reprod 2002, 66(1):6-13.

7. Li N, Wells DN, Peterson AJ, Lee RS: Perturbations in the biochemical composition of fetal fluids are apparent in surviving bovine somatic cell nuclear transfer pregnancies in the first half of gestation. Biol Reprod 2005, 73(1):139-148.

8. Coan PM, Burton GJ, Ferguson-Smith AC: Imprinted genes in the placenta-a review. Placenta 2005, 26(Suppl A):S10-20.

9. Higashimoto K, Soejima H, Saito T, Okumura K, Mukai T: Imprinting disruption of the CDKN1C/KCNQ1OT1 domain: the molecular mechanisms causing Beckwith-Wiedemann syndrome and cancer. Cytogenet Genome Res 2006, 113(1-4):306-312.

10. Diaz-Meyer N, Day CD, Khatod K, Maher ER, Cooper W, Reik W, Junien C, Graham G, Algar E, Der Kaloustian VM, et al: Silencing of CDKN1C (p57KIP2) is associated with hypomethylation at KvDMR1 in BeckwithWiedemann syndrome. J Med Genet 2003, 40(11):797-801.

11. Arima T, Kamikihara T, Hayashida T, Kato K, Inoue T, Shirayoshi $Y$, Oshimura M, Soejima H, Mukai T, Wake N: ZAC, LIT1 (KCNQ1OT1) and p57KIP2 (CDKN1C) are in an imprinted gene network that may play a role in Beckwith-Wiedemann syndrome. Nucleic Acids Res 2005, 33(8):2650-2660.

12. DeBaun MR, Niemitz EL, Feinberg AP: Association of in vitro fertilization with Beckwith-Wiedemann syndrome and epigenetic alterations of LIT1 and H19. Am J Hum Genet 2003, 72(1):156-160.

13. Weksberg R, Smith AC, Squire J, Sadowski P: Beckwith-Wiedemann syndrome demonstrates a role for epigenetic control of normal development. Hum Mol Genet 2003, 12(Spec No 1):R61-68.

14. Yang L, Chavatte-Palmer P, Kubota C, O'Neill M, Hoagland T, Renard JP, Taneja M, Yang X, Tian XC: Expression of imprinted genes is aberrant in deceased newborn cloned calves and relatively normal in surviving adult clones. Molecular Reproduction \& Development 2005, 71(4):431-438

15. Yang L, Chavatte-Palmer P, Kubota C, O'Neill M, Hoagland T, Renard JP, Taneja M, Yang X, Tian XC: Expression of imprinted genes is aberrant in deceased newborn cloned calves and relatively normal in surviving adult clones. Mol Reprod Dev 2005, 71(4):431-438.

16. Li S, Li Y, Yu S, Du W, Zhang L, Dai Y, Liu Y, Li N: Expression of insulin-like growth factors systems in cloned cattle dead within hours after birth. Molecular Reproduction \& Development 2007, 74(4):397-402.

17. Bird A: DNA methylation patterns and epigenetic memory. Genes \& Development 2002, 16(1):6-21.

18. Morgan HD, Santos F, Green K, Dean W, Reik W: Epigenetic reprogramming in mammals. Hum Mol Genet 2005, 14(Spec No 1):R47-58.

19. Li E: Chromatin modification and epigenetic reprogramming in mammalian development. Nature Reviews Genetics 2002, 3(9):662-673.

20. Haaf T: Methylation dynamics in the early mammalian embryo: implications of genome reprogramming defects for development. Curr Top Microbiol Immunol 2006, 310:13-22.

21. Aranyi T, Paldi A: The constant variation: DNA methylation changes during preimplantation development. FEBS letters 2006, 580(2829):6521-6526.

22. Young $L E$, Beaujean $N$ : DNA methylation in the preimplantation embryo: the differing stories of the mouse and sheep. Anim Reprod Sci 2004, 82-83:61-78.

23. Bourc'his D, Le Bourhis D, Patin D, Niveleau A, Comizzoli P, Renard JP, Viegas-Pequignot E: Delayed and incomplete reprogramming of chromosome methylation patterns in bovine cloned embryos. Curr Biol 2001, 11(19):1542-1546.

24. Cezar GG, Bartolomei MS, Forsberg EJ, First NL, Bishop MD, Eilertsen KJ: Genome-wide epigenetic alterations in cloned bovine fetuses. Biol Reprod 2003, 68(3):1009-1014.

25. Lucifero D, Suzuki J, Bordignon V, Martel J, Vigneault C, Therrien J, Filion F, Smith LC, Trasler JM: Bovine SNRPN methylation imprint in oocytes and day 17 in vitro produced and somatic cell nuclear transfer embryos. Biol Reprod 2006, 75(4):531-538.

26. Chen T, Jiang Y, Zhang YL, Liu JH, Hou Y, Schatten H, Chen DY, Sun QY: DNA hypomethylation of individual sequences in aborted cloned bovine fetuses. Front Biosci 2005, 10:3002-3008.

27. Dean W, Santos F, Stojkovic M, Zakhartchenko V, Walter J, Wolf E, Reik W: Conservation of methylation reprogramming in mammalian development: aberrant reprogramming in cloned embryos. Proc Natl Acad Sci USA 2001, 98(24):13734-13738.

28. Dindot SV, Farin PW, Farin CE, Romano J, Walker S, Long C, Piedrahita JA: Epigenetic and genomic imprinting analysis in nuclear transfer derived Bos gaurus/Bos taurus hybrid fetuses. Biol Reprod 2004, 71(2):470-478.

29. Kang YK, Park JS, Koo DB, Choi YH, Kim SU, Lee KK, Han YM: Limited demethylation leaves mosaic-type methylation states in cloned bovine pre-implantation embryos. Embo J 2002, 21(5):1092-1100.

30. Kang YK, Yeo S, Kim SH, Koo DB, Park JS, Wee G, Han JS, Oh KB, Lee KK, Han YM: Precise recapitulation of methylation change in early cloned embryos. Mol Reprod Dev 2003, 66(1):32-37.

31. Hiendleder S, Mund C, Reichenbach HD, Wenigerkind H, Brem G, Zakhartchenko V, Lyko F, Wolf E: Tissue-specific elevated genomic cytosine methylation levels are associated with an overgrowth phenotype of bovine fetuses derived by in vitro techniques. Biol Reprod 2004, 71(1):217-223.

32. Wells DN, Forsyth JT, McMillan V, Oback B: The health of somatic cell cloned cattle and their offspring. Cloning Stem Cells 2004, 6(2):101-110.

33. Ortegon H, Betts DH, Lin L, Coppola G, Perrault SD, Blondin P, King WA: Genomic stability and physiological assessments of live offspring sired by a bull clone, Starbuck II. Theriogenology 2007, 67(1):116-126.

34. Geuns E, De Rycke M, Van Steirteghem A, Liebaers I: Methylation imprints of the imprint control region of the SNRPN-gene in human gametes and preimplantation embryos. Hum Mol Genet 2003, 12(22):2873-2879.

35. Glenn CC, Nicholls RD, Robinson WP, Saitoh S, Niikawa N, Schinzel A, Horsthemke B, Driscoll DJ: Modification of 15q11-q13 DNA methylation imprints in unique Angelman and Prader-Willi patients. Hum Mol Genet 1993, 2(9):1377-1382.

36. Maher ER, Brueton LA, Bowdin SC, Luharia A, Cooper W, Cole TR, Macdonald F, Sampson JR, Barratt CL, Reik W, et al: Beckwith-Wiedemann 
syndrome and assisted reproduction technology (ART). J Med Genet 2003, 40(1):62-64

37. Gicquel C, Gaston V, Mandelbaum J, Siffroi JP, Flahault A, Le Bouc Y: In vitro fertilization may increase the risk of Beckwith-Wiedemann syndrome related to the abnormal imprinting of the KCN1OT gene. Am J Hum Genet 2003, 72(5):1338-1341.

38. Coolen MW, Statham AL, Gardiner-Garden M, Clark SJ: Genomic profiling of CpG methylation and allelic specificity using quantitative highthroughput mass spectrometry: critical evaluation and improvements. Nucleic Acids Res 2007, 35(18):e119.

39. Ledgard A, Lee RS, Couldrey C, Peterson J: Dickkopf-1 Expression During Early Bovine Placentation and Its Down-regulation in Somatic Cell Nuclear Transfer (SCNT) Pregnancies. J Reprod Dev 2009, 55(5):467-474

40. Lee RS, Peterson AJ, Donnison MJ, Ravelich S, Ledgard AM, Li N, Oliver JE, Miller AL, Tucker FC, Breier B, et al: Cloned cattle fetuses with the same nuclear genetics are more variable than contemporary half-siblings resulting from artificial insemination and exhibit fetal and placental growth deregulation even in the first trimester. Biol Reprod 2004, 70(1):1-11.

41. Misica-Turner PM, Oback FC, Eichenlaub M, Wells DN, Oback B: Aggregating embryonic but not somatic nuclear transfer embryos increases cloning efficiency in cattle. Biol Reprod 2007, 76(2):268-278

42. Schurmann A, Wells DN, Oback B: Early zygotes are suitable recipients for bovine somatic nuclear transfer and result in cloned offspring. Reproduction 2006, 132(6):839-848.

43. Green AL, Wells DN, Oback B: Cattle cloned from increasingly differentiated muscle cells. Biol Reprod 2007, 77(3):395-406.

44. Kremenskoy M, Kremenska Y, Suzuki M, Imai K, Takahashi S, Hashizume K, Yagi S, Shiota K: DNA methylation profiles of donor nuclei cells and tissues of cloned bovine fetuses. J Reprod Dev 2006, 52(2):259-266.

45. Laird CD, Pleasant ND, Clark AD, Sneeden JL, Hassan KM, Manley NC, Vary JC Jr, Morgan T, Hansen RS, Stoger R: Hairpin-bisulfite PCR: assessing epigenetic methylation patterns on complementary strands of individual DNA molecules. Proc Natl Acad Sci USA 2004, 101(1):204-209.

46. Li LC, Dahiya R: MethPrimer: designing primers for methylation PCRs. Bioinformatics 2002, 18(11):1427-1431.

47. Gebert C, Wrenzycki C, Herrmann D, Groger D, Reinhardt R, Hajkova P, Lucas-Hahn A, Carnwath J, Lehrach H, Niemann H: The bovine IGF2 gene is differentially methylated in oocyte and sperm DNA. Genomics 2006, 88(2):222-229

48. Szyf M, Weaver IC, Champagne FA, Diorio J, Meaney MJ: Maternal programming of steroid receptor expression and phenotype through DNA methylation in the rat. Front Neuroendocrinol 2005, 26(3-4):139-162.

49. Weaver IC, Cervoni N, Champagne FA, D'Alessio AC, Sharma S, Seckl JR, Dymov S, Szyf M, Meaney MJ: Epigenetic programming by maternal behavior. Nat Neurosci 2004, 7(8):847-854.

50. Weaver IC, Champagne FA, Brown SE, Dymov S, Sharma S, Meaney MJ, Szyf M: Reversal of maternal programming of stress responses in adult offspring through methyl supplementation: altering epigenetic marking later in life. J Neurosci 2005, 25(47):11045-11054.

51. Sambrook J, Fritsch EF, Maniatus T: Molecular cloning a laboratory manual. Cold Spring Harbor, New York: Cold Spring Harbor Laboratory Press, 21989.

52. Ehrich M, Nelson MR, Stanssens P, Zabeau M, Liloglou T, Xinarianos G, Cantor CR, Field JK, Boom van den D: Quantitative high-throughput analysis of DNA methylation patterns by base-specific cleavage and mass spectrometry. Proc Natl Acad Sci USA 2005, 102(44):15785-15790.

53. Boom van den $D$, Ehrich M: Mass spectrometric analysis of cytosine methylation by base-specific cleavage and primer extension methods. Methods in molecular biology (Clifton, NJ) 2009, 507:207-227.

doi:10.1186/1471-213X-10-27

Cite this article as: Couldrey and Lee: DNA methylation patterns in tissues from mid-gestation bovine foetuses produced by somatic cell nuclear transfer show subtle abnormalities in nuclear reprogramming. BMC Developmental Biology 2010 10:27.

\section{Submit your next manuscript to BioMed Central and take full advantage of:}

- Convenient online submission

- Thorough peer review

- No space constraints or color figure charges

- Immediate publication on acceptance

- Inclusion in PubMed, CAS, Scopus and Google Scholar

- Research which is freely available for redistribution

Submit your manuscript at www.biomedcentral.com/submit 